\title{
Domestic violence and child mortality in the developing world
}

Article

Accepted Version

Rawlings, S. and Siddique, Z. (2020) Domestic violence and child mortality in the developing world. Oxford Bulletin of Economics and Statistics, 82 (4). pp. 723-750. ISSN 14680084 doi: https://doi.org/10.1111/obes.12357 Available at https://centaur.reading.ac.uk/88545/

It is advisable to refer to the publisher's version if you intend to cite from the work. See Guidance on citing.

To link to this article DOI: http://dx.doi.org/10.1111/obes.12357

Publisher: Blackwell Publishing Ltd

All outputs in CentAUR are protected by Intellectual Property Rights law, including copyright law. Copyright and IPR is retained by the creators or other copyright holders. Terms and conditions for use of this material are defined in the End User Agreement.

\section{www.reading.ac.uk/centaur}

\section{CentAUR}

Central Archive at the University of Reading

Reading's research outputs online 


\title{
Domestic violence and child mortality in the developing world *
}

\author{
Samantha Rawlings ${ }^{\dagger} \quad$ Zahra Siddique ${ }^{\ddagger}$ \\ Forthcoming in Oxford Bulletin of Economics and Statistics
}

\begin{abstract}
We examine the effect of domestic violence on child mortality using Demographic and Health Surveys from thirty-two developing countries. We first examine conditional associations between violence faced by the mother and child mortality after controlling for observable confounders. Children of (ever) physically victimized mothers are $0.4,0.7$, and 1.0 pp more likely to die within thirty days, a year, and five years of being born. We find similar associations when examining violence experienced in the last twelve months, although these are no longer statistically significant. The association is statistically significant, and larger, if the mother experiences violence in the last twelve months often, rather than sometimes. Violence is significantly associated with pregnancy loss, suggesting the true effect on mortality is larger than estimates based on live-births would suggest. We investigate robustness of associations to omitted variable bias, assessing the role of selection on unobservables to estimate lower bounds on the true effect. These continue to indicate economically meaningful positive effects, suggesting selection on unobservables would need to be 2.4-3 times that of selection on observables to nullify the estimated effect. We provide evidence that maternal smoking and breastfeeding practices are mediators in the relationship between domestic violence and child mortality.
\end{abstract}

\section{JEL Classification: I14, J12, J13 Keywords: Child Mortality, Domestic Violence}

\footnotetext{
*The authors have no conflicts of interest to declare. Earlier versions of this paper were circulated as 'Domestic violence and child mortality' and 'Domestic abuse and child health'. We have benefited from comments by seminar and conference participants at the University of Reading, CESIfo Munich, the Institute of Development and Economic Alternatives in Lahore (Pakistan), the University of Cologne, the 2015 IZA/World Bank conference, the Royal Economic Society Conference, the European Society of Population Economics conference as well as comments by Sonia Bhalotra, Marina Della Giusta, Uma Kambhampati, Andrew Oswald, Christopher Taber and Charlotte Watts. Thanks also to the editor, Climent Quintana-Domeque, and two anonymous referees for comments and suggestions which greatly improved the paper. All errors are our own.

${ }^{\dagger}$ Corresponding author: Department of Economics, University of Reading, Whiteknights, Reading RG6 6AA, UK. E-mail: s.b.rawlings@reading.ac.uk. Phone: +44 (0) 1183788231

${ }^{\ddagger}$ Department of Economics, University of Bristol, The Priory Road Complex, Priory Road, Bristol, BS8 1TU, UK. E-mail: zahra.siddique@bristol.ac.uk
} 


\section{Introduction}

Domestic violence, defined as physical and/or sexual violence by an intimate partner, has important consequences for large numbers of female victims across the globe. Using data from 81 countries, Devries et al. (2013) note that 'globally, in 2010, 30.0\% [95\% confidence interval (CI) 27.8 to $32.2 \%$ ] of women aged 15 and over have experienced, during their lifetime, physical and/or sexual intimate partner violence.' These prevalence rates are particularly high in developing regions such as Central Sub-Saharan Africa (65.64\%) and South Asia (41.73\%).

Domestic violence has direct costs borne by victims: it is one of the leading causes of homicide deaths among women, as well as being associated with poor health and reduced earnings. An empirical literature in public heath and medicine has also examined the relationship between domestic violence experienced by mothers and health outcomes of their children, documenting a negative correlation between the two (see Yount et al., 2011). However, much of this literature uses small non-random samples from developed countries and does not account for omitted variables which are potentially correlated with both domestic violence and child health. ${ }^{1}$ We use nationally representative data sets from thirty-two developing countries to investigate this relationship, and we provide a careful examination of potential omitted variable bias.

Two relatively recent studies in health economics examine the relationship between assaults during pregnancy and birth outcomes using large scale administrative data from the US. Aizer (2011) uses data on female hospitalizations and birth outcomes for the state of California between 1991 and 2002. She finds that serious incidents of domestic violence (where serious is defined as resulting in hospitalization) cause a reduction in birth weight of 163 grams. Currie et al. (2018) examine the impact of assaults during pregnancy on infant health outcomes using linked administrative data from New York City and find a robust negative effect of assaults on birth outcomes. A key distinction of our paper from both Aizer (2011) and Currie et al. (2018) is that by the nature of their data they focus on serious cases of domestic violence, that result in either hospitalistion (in the case of Aizer, 2011), or a report of assault to the police (in the case of Currie et al., 2018). Instead, we examine both severe and less severe forms of violence that occur within the home but do not result

\footnotetext{
${ }^{1}$ A large-scale study was carried out by Silverman et al. (2006), who use data on women giving birth in 26 US states as part of the 2000-2003 Pregnancy Risk Assessment Monitoring System. They find that women experiencing intimate partner violence are at increased risk for poor maternal health (such as high blood pressure, vaginal bleeding, severe nausea/vomiting/dehydration, kidney or urinary tract infections, frequent hospital visits) as well as poor infant health (such as delivery pre-term, low birth-weight, more likely to require intensive care).
} 
in hospitalisation or reporting to the authorities. A further difference is the geographical focus of our study. While Aizer (2011) and Currie et al. (2018) focus on the US (California and New York City), our study is about developing countries. Rates of domestic violence in developing countries tend to be higher, particularly violence experienced in the last 12 months. In the US, around $30 \%$ of women experience physical domestic violence in their lifetime, and around $4 \%$ in the last 12 months (Black et al., 2011). In contrast, in our sample, rates are higher in the majority of countries, with highs of almost $60 \%$ lifetime prevalence and $50 \%$ in the last 12 months (Figures A2 and A3).

A key contribution of our paper is the use of data from the Demographic and Health Surveys (DHS), containing comparable information on domestic violence and child mortality across a wide range of developing countries over a fifty year period. ${ }^{2}$ In a related study to ours, Chai et al. (2016) investigate the association between domestic violence and child stunting/wasting in twentynine countries between 1998 and 2012. They find a positive association between maternal lifetime exposure to domestic violence and stunting in children, after controlling for confounding factors. Our study builds upon and differs from theirs in a number of dimensions. They consider only the youngest child of the mother, and focus on mother's life time experience of domestic violence. We instead consider lifetime experience of abuse and the mortality of all her children, whilst also examining the relationship between violence in the last twelve months and neonatal mortality of the most recent child born to a woman. Our data, therefore, is significantly expanded from theirs, allowing us to utilize information on approximately 1.3 million children born between 1966 and 2016 in our baseline estimations. Furthermore, we consider child mortality as our outcome of interest, rather than anthropometric outcomes of children which are conditional on survival to date of interview. Therefore we are able to consider outcomes of all live births occurring to the mother, so that survivorship bias is minimised, and we additionally investigate whether our results are attenuated by mortality in utero. ${ }^{3}$

We are able to quantify the association between physical and sexual violence by intimate partners on child mortality at thirty days, one year and five years after birth. We condition on a comprehen-

\footnotetext{
${ }^{2}$ In a publication produced by MeasureDHS, the data providers for the DHS data, Kishor and Johnson (2004a) profile the experience of domestic violence across nine countries using DHS and provide summary statistics for the incidence of child mortality across victims and non-victims. However, they only present differences in means, do not control for any confounding factors, and do not perform any regression analysis.

${ }^{3}$ The issue of survivorship bias is discussed more fully in Chai et al. (2016), although they do not investigate the extent to which this might affect their results. We investigate the extent to which survivorship bias might affect our results by considering the conditional association of violence and non-live births.
} 
sive set of pre-determined controls. This allows us to compare mortality of children whose mothers have been victims of violence to those of reasonably similar children whose mothers have not been victims. In our baseline specifications, we find that children born in families where the mother was (ever) a victim of domestic physical violence are $0.4,0.7$ and 1.0 percentage points more likely to die within thirty days, one year and five years of being born. All these effects are statistically significant and sizeable, given that just $3 \%$ of all children born to non-victims in our sample die within thirty days, $6.2 \%$ die within one year and $9.2 \%$ die within five years of being born. We also utilise methods suggested by Altonji et al. (2005) and Oster (2019) to assess the sensitivity of our estimates to omitted variable bias. We produce a lower bound on the effect of domestic violence on child mortality, assuming that selection on unobservable factors is as important as selection on observable factors. We find this lower bound still suggests an economically meaningful and strong positive relationship between domestic violence and child mortality.

We also use a measure of domestic violence faced by the mother in the twelve months preceding the survey. We find similar results, although our smaller sample size limits statistical power in detecting effects: children whose mothers were a victim of physical violence in the last twelve months are 0.4 percentage points more likely to die within thirty days of being born. This effect is sizeable given that just $2.3 \%$ of all children born to non-victims in our sample die within thirty days. Investigating frequency of violence, we find that these effects are driven by women who experienced violence often - as opposed to sometimes - over the last twelve months.

We also investigate whether there is evidence that our sample of live births is selectively healthy and shaped by mortality selection during the in utero period. We utilise information from DHS pregnancy calendars, which contain information on all pregnancy outcomes in the previous five years, and examine pregnancy loss over this time. We find a strong and statistically significant positive association between violence experienced in the last twelve months and pregnancy loss, suggesting the true effect of violence experienced by the mother on child mortality is potentially larger than our estimates based on live births would suggest.

Finally, we investigate potential pathways underlying these effects, drawing on the medical literature to identify potential mediators. We find that violence is associated with a range of potential mediators, including maternal health, smoking (a measure of risky behaviour), prenatal care and breastfeeding practice. Once we account for the potential role of unobserved selection, 
however, we find evidence that unobserved selection accounts for much of the association between violence and prenatal care and between violence and maternal health. In contrast, the association between violence and maternal smoking as well as between violence and breastfeeding practices appears to be more robust to unobserved selection. Effects of violence on breastfeeding initiation are small relative to the mean, though statistically significant. We find large effects of violence on smoking behaviour; physical violence is associated with a 3 percentage point increase in the likelihood that a woman smokes, which is large relative to the mean in the sample $(4.9 \%)$.

In the next section, we describe the data set and variables used in our work. In section 3 we provide the framework of analysis which we use. We then go on to describe our estimation results and their implications in section 4 . Section 5 examines the role of selection, and section 6 investigates potential mechanisms. Section 7 concludes.

\section{Data}

Data for our analysis comes from the Demographic and Health Surveys (DHS). ${ }^{4}$ These are nationally representative surveys that collect information on fertility, health, family planning, and socioeconomic status at the community, household, and individual levels. Ever-married women age 18-49 are interviewed and complete fertility histories are collected so that information on all births and any deaths of children respondents have ever had is documented. Surveys are based on standardised questionnaires and thus are comparable across countries. We use 54 surveys from 32 different countries, all carried out between the years 2000 and $2016 .^{5}$

Inclusion in our estimation sample is conditional on the surveys including the DHS domestic violence questionnaire module. Table A1 details the surveys used, while Figure A1 shows a map of countries included in our estimation sample.

\subsection{Domestic violence}

Questions in the domestic violence module within the DHS are based on the Conflict Tactics Scale approach to eliciting information on violence (Straus, 1979). Women interviewed for the domestic violence module are asked a series of questions concerning the behavior of their current partner,

\footnotetext{
${ }^{4}$ The data are available at www.measuredhs.com.

${ }^{5}$ Questions concerning domestic violence were asked in earlier surveys in some countries, but it was not until 1998-9 that the DHS created a standardised questionnaire for domestic violence (Kishor and Johnson, 2004b).
} 
or former partner if currently un-partnered. Misreporting of domestic violence in the DHS due to privacy concerns is likely to be low since the DHS tries to minimize this through respondent selection, interviewer training and interview method. Only one eligible woman per household is selected/interviewed for the domestic violence module, with extensive training provided to interviewers on the appropriate way to ask sensitive questions. Domestic violence questions are asked at the end of an interview to ensure a rapport has already been built between interviewer and interviewee, domestic violence questions are asked only if absolute privacy is ensured and translators are avoided to ensure privacy. ${ }^{6}$

Within the domestic violence module, women are asked 7 questions concerning whether their partner had ever carried out any specific physical violence acts (e.g. pushing, shaking, slapping, twisting the woman's arm, punching, kicking, etc.). They are also asked 3 questions concerning sexual violence (e.g. whether her partner had ever physically forced her to have sexual intercourse with him). ${ }^{7}$ Our domestic violence measures are constructed from these questions, which include whether or not the woman ever suffered i) physical violence, and ii) sexual violence.

Whilst all surveys in our estimation sample collect information on physical violence, two surveys carried out in Bangladesh and Pakistan do not collect information on sexual violence. Also, surveys in Jordan do not ask a complete set of questions concerning sexual violence ever experienced. These surveys are dropped from regressions examining the effect of sexual violence on child mortality. Our estimation sample when examining the effect of physical violence is therefore larger than when examining the effect of sexual violence (see Table A1).

Since 2005, the DHS domestic violence module has also included questions on whether the types of violence described above were experienced in the last twelve months and we use this in further analysis. Table A1 shows the surveys for which this information is available. Our violence measures are then indicators for whether a woman suffered i) physical violence and ii) sexual violence in the last twelve months. ${ }^{8}$ Additional descriptives are given in the Appendix.

\footnotetext{
${ }^{6}$ Recent work by Agüero and Frisancho (2018) find that college educated women under-report physical and sexual violence while there is no such bias among the less educated. Since this work has not been replicated apart from the original setting (impoverished peri-urban districts in Lima, Peru), it is unclear whether these results generalize to other settings/countries.

${ }^{7}$ There is minor variation across countries in the questions asked; for example, in some surveys, 'country-specific' questions concerning abusive acts are also included. Information on emotional abuse is also collected (e.g. "Has your husband every humiliated you") but we do not use these measures in our analysis as they are more subjective.

${ }^{8}$ There are six countries (Bangladesh, Cameroon, Colombia, Jordan, Pakistan, and Rwanda) for which information on sexual violence in the last twelve months is not collected, so that again, our estimation sample when examining the effect of recent physical violence is larger than when examining the effect of recent sexual violence.
} 


\subsection{Child mortality}

The DHS includes complete fertility histories provided by the woman as well as information on the age of any children at death. This allows us to construct measures of individual child mortality. In contrast to child health measures such as height and/or weight, information on child mortality is not conditional on survival to interview and we have information on the mortality outcomes of all live births a woman has had. ${ }^{9}$ We focus on neonatal (thirty days), infant (twelve months) and under five (sixty months) mortality. ${ }^{10}$ Since age heaping is observed in the data, we include the thirtieth day, twelfth and sixtieth months in each of these measures.

We also exclude from our analysis any children for whom the information is right censored, i.e. those who are younger than these thresholds at the time of the survey. Given these restrictions, we have a sample of approximately 1.47, 1.40, and 1.12 million children born between 1966 and 2011 for neonatal, infant and under-five mortality in our baseline specifications when we use measures of violence ever experienced by mothers. These sample sizes are reduced to 1.14, 1.09, and 0.86 million children once we condition on observable characteristics. When we examine domestic violence experienced by mothers in the last twelve months our estimation sample is substantially reduced to approximately 56,000 children (45,000 once conditioning on observable characteristics) born in the last 12 months, which we use to examine neonatal mortality only. Additional descriptives are given in the Appendix.

\subsection{Differences across female victims and non-victims}

Average child mortality is higher amongst children born to female victims as compared to nonvictims of domestic violence (Figures 1 and 2). These differences are statistically significant, although the confidence intervals are wider when we consider violence experienced and births occurring in the last twelve months only due to the reduced sample size. Table A2 shows the means of child mortality outcomes, as well as all control variables used in our analysis, across the sub-samples

\footnotetext{
${ }^{9}$ There is a possibility of mortality selection in our sample if deaths occur in utero as a result of domestic violence; in section 3.2 we investigate whether this may be the case.

${ }^{10} \mathrm{It}$ is possible that there is potential measurement error in terms of timing of the event of mortality since these are constructed from recall data. However, we believe that for a serious event in the life of a woman such as death of a child such measurement error is likely to be low. A related concern might be that age at death may be incorrectly reported. However, there is no a priori reason to believe that either source of such potential measurement error would be systematically correlated with the explanatory variables in our regressions so our estimates should remain unbiased. Such measurement error in the dependent variable will primarily lead to imprecision in estimates and lower $R^{2}$ statistics (Oster, 2019).
} 
of children whose mothers ever experienced physical violence (Table A2) and experienced physical violence in the last twelve months (Table A3). ${ }^{11}$ For all mortality measures, average mortality is always higher among sub-samples of children whose mothers were ever victims of physical violence. Similarly, average neonatal mortality is higher among children of victims of physical violence in the last twelve months compared to children of non-victims. This is also true when we compare victims of violence in the last twelve months to those women who ever experienced violence, but not in the last twelve months (Table A4). ${ }^{12}$

While these comparisons strongly suggest a positive association between domestic violence and child mortality, the sub-samples are different in other, potentially important ways. Table A2 also shows that women who are victims of physical violence are generally less educated than non-victims, their partners are less educated compared to partners of non-victims, they are more likely to reside in rural areas, and the age difference between themselves and their partners is larger. These differences are statistically significant. ${ }^{13}$ To address observable differences in characteristics of victims vs. non victims, we include a comprehensive set of pre-determined controls in our baseline regressions. Since we cannot rule out the presence of potential unobservable confounding factors when estimating our regressions (for instance related to socio-economic status and family background) that are likely to be correlated with domestic violence, we also investigate the robustness of our results to potential omitted variable bias after making assumptions on how selection on observables is related to selection on unobservables, as in Altonji et al. (2005) and Oster (2019).

\footnotetext{
${ }^{11}$ We use physical violence since this provides us with the largest sample; similar patterns are apparent when we consider sexual violence.

${ }^{12}$ Again, we find similar results when we make these comparisons for victims of sexual violence. These additional summary statistics are available on request.

${ }^{13}$ Differences are also apparent when we split the sample into women who have never experienced violence, those who experienced it in the last twelve months, and those who previously experienced violence but not in the last twelve months (Table A4).
} 


\section{Empirical Framework}

\subsection{Adjusting for observable factors}

\subsubsection{Violence ever experienced}

We investigate the relationship between child mortality and domestic violence using linear probability models (LPM) in the following baseline empirical specification: ${ }^{14}$

$$
C_{i j s t}^{k}=\beta_{0}^{k, l}+\beta_{1}^{k, l} V i o_{i j s}^{l}+X_{i j t}^{\prime} \beta_{3}^{k, l}+\gamma_{s}+\tau_{t}+\sigma_{j \times t}+\eta_{r}+\epsilon_{i j s t}^{k, l} .
$$

The dependent variable $C_{i j s t}^{k}$ is measure $k$ of child mortality for child $i$ born in country $j$ at time $t$ whose mother is a respondent to a DHS survey in year $s$. We estimate regressions where we use binary indicators for neonatal $(k=n e o)$, infant $(k=$ infant $)$ and under-5 $(k=$ under 5$)$ mortality for $C_{i j s t}^{k}$. $V i o_{i j s}^{l}$ is measure $l$ of domestic violence reported by the mother of child $i$ born in country $j$ in a DHS survey in year $s$. We investigate (in separate regressions) indicators which take the value one if the mother of child $i$ born in country $j$ at time $t$ ever experienced physical violence $(l=$ physical $)$, or sexual violence $(l=$ sexual $)$ from her partner. ${ }^{15}$

We include a vector of control variables $X_{i j t}$, containing pre-determined variables which differ between children whose mothers are victims of violence and those whose mothers are not victims (see section 2.3). ${ }^{16}$ This includes parental characteristics such as mother and father's education, and the age gap between mothers and their spouses. ${ }^{17}$ We include an indicator for whether the household is located in an urban area. The DHS data do not contain information on household income, and income itself may be affected by domestic violence, so we use parental education and urban status - all of which we might expect to improve child health outcomes - to capture income

\footnotetext{
${ }^{14}$ Although we report results from using a linear model, our results are robust to the use of a probit model with marginal effects almost identical to the linear model (results available on request).

${ }^{15}$ Whilst we use these dummy variables in our main analysis, our results are also robust to using indices of violence. Specifically, following the procedure first described by Kling et al. (2007) and later implemented by Erten and Keskin (2018) in the context of domestic violence using DHS data, we constructed indices of violence based on the underlying questions on specific acts of violence. Our results using indices rather than binary variables for violence remain unchanged. The results using violence indices are available on request.

${ }^{16}$ In order to avoid bias in our estimates, we do not control for potentially endogenous controls which themselves may be outcomes of domestic violence, such as any characteristics of the child, the current wealth of the household, or marital status of the woman. Our results are, however, robust to their inclusion. Results available on request.

${ }^{17}$ We do not include religion since it is not recorded for all the countries in our sample. However, in section 5 , we show that our results are robust to the inclusion of religion dummies.
} 
gradients in health. We include fixed effects for survey year $\left(\gamma_{s}\right)$, year of birth $\left(\tau_{t}\right)$, country $\times$ year of birth $\left(\sigma_{j \times t}\right)$, as well as sub-national region dummies $\left(\eta_{r}\right)$. The use of country $\times$ year of birth fixed effects ensures we use within country and child year of birth variation only to identify the effect of domestic violence on child mortality. $\epsilon_{i j s t}$ is the error term. We use robust standard errors which adjust for clustering at the country level. Since the number of clusters in our analysis is only thirty two, and since the cluster sizes are very different, ${ }^{18}$ we also compute and report wild bootstrap p-values, as discussed in Cameron et al. (2008) and MacKinnon (2019). Since the wild bootstrap tends to slightly over reject when cluster sizes vary widely (MacKinnon and Webb, 2017), as in our case, the reported p-values are conservative.

\subsubsection{Violence experienced in the last twelve months}

A potential concern with estimation results from (1) is that while we know whether the mother ever experienced domestic violence, absent timing on when this occurred, we do not know if the child was exposed to this violence. For instance, a child may have been exposed to violence at age three but was therefore not exposed when at risk of, say, infant mortality. Therefore we also estimate regressions using recent violence:

$$
C_{i j s t}^{n e o}=\beta_{0}^{n e o, l}+\beta_{1}^{n e o, l} \text { VioRecent } t_{i j s}^{l}+X_{i j t}^{\prime} \beta_{2}^{n e o, l}+\gamma_{s}+\tau_{t}+\sigma_{j \times t}+\eta_{r}+\epsilon_{i j s t}^{n e o, l},
$$

where VioRecent $_{i j s}^{l}$ indicates whether or not domestic violence occurred in the twelve months preceding the survey. As before, we estimate regressions where we use indicators for VioRecent $t_{i j s}$ which take the value one if the mother of child $i$ born in country $j$ reported experiencing physical violence $(l=$ physical $)$, and sexual violence $(l=$ sexual $)$ from their partner over the last twelve months in a DHS survey in year $s$. These measures are only available for surveys administered after 2005 (see Table A1), so our sample size is considerably reduced from before. We also restrict our estimation sample to births occurring in the twelve months preceding each survey to ensure, as much as possible given these data, that timing of violence and birth overlap. A caveat is that we do not know with certainty that children were exposed to the violence described by their mother; it

\footnotetext{
${ }^{18}$ In our largest sample, once we condition on $X_{i j t}$, our sample sizes by country vary from 2,830 in Ukraine to 297,482 in India.
} 
still might be the case that violence occurs only after a child is born and not before, although this concern is likely to be less important for recent violence than for ever experienced violence. Here, the dependent variable $C_{i j s t}^{n e o}$ is an indicator for neonatal mortality. There are no children completely exposed to infant or under-5 mortality risk who were born in the twelve months preceding the survey. We therefore do not investigate infant or under-5 mortality in this specification.

As in equation (1), we include the same set of control variables $X_{i j t}$, survey year fixed effects $\left(\gamma_{s}\right)$, year of birth fixed effects $\left(\tau_{t}\right)$, country $\times$ year fixed effects $\left(\sigma_{j \times t}\right)$, and region fixed effects $\left(\eta_{r}\right)$. As before, we report robust standard errors which adjust for clustering at the country level, as well as wild bootstrap p-values.

Women are also asked the frequency with which any violence occurred in the last twelve months. We use this information to investigate whether severity of violence (as measured by frequency) matters. We estimate the specifications:

$$
C_{i j s t}^{n e o}=\beta_{0}^{n e o, l}+\beta_{1}^{n e o, l} V i o S o m e_{i j s}^{l}+\beta_{2}^{n e o, l} V_{i o O f t e n}^{l}{ }_{i j s}+X_{i j t}^{\prime} \beta_{3}^{n e o, l}+\gamma_{s}+\tau_{t}+\sigma_{j \times t}+\eta_{r}+\epsilon_{i j s t}^{n e o, l} .
$$

Here, VioSome ${ }_{i j s}^{l}$ is a dummy variable for whether the women reported experiencing violence sometimes and $V i o O$ ften $_{i j s}^{l}$ is a dummy variable indicating whether the woman reported experiencing violence often. The (excluded) base category refers to women who never experienced violence. In all other respects, equation $(2 \mathrm{~b})$ is identical to equation $(2 \mathrm{a})$.

\subsection{Selective mortality and the role of unobservable factors}

\subsubsection{Mortality selection}

Since we have information on the mortality status of all children ever born to a woman in our sample, our measures of child mortality have the advantage over anthropometric indicators that they are not conditional on survival to interview. This avoids concerns around so-called survivorship bias that plague analysis using anthropometric measures of child health.

Nonetheless, selective mortality may affect our estimates of the impact of violence on child health if deaths occur in utero as a result of violence. We investigate if this is the case, using information from DHS Contraceptive (Reproductive) Calendar Data. 22 (30) of the countries (surveys) in 
our sample contain a DHS Reproductive Calendar module (see Table A1). This asks respondents information regarding contraceptive use, fertility, and pregnancy outcomes since the beginning of the DHS calendar. The DHS calendar for a particular survey is set at five calendar years prior to the beginning of the survey. ${ }^{19}$ Women are asked the following question: "Did you have a pregnancy that ended in miscarriage, abortion, or stillbirth?'. Additionally, for all (successful and unsuccessful) pregnancies, a woman is asked the month a pregnancy started, and the month it ended, allowing us to construct measures of all pregnancy outcomes over the last twelve months and match these outcomes to violence experienced over the same period.

A disadvantage of the way this question is framed is that it does not distinguish between spontaneous and induced abortion (i.e. between pregnancy loss and abortion). To address this issue, we focus on any loss occurring at or past seven months gestation (classified by the DHS as stillbirth), since this is less likely to be the result of induced abortion, and drop pregnancies that were lost at earlier gestation from the analysis. ${ }^{20}$

Using information on violence experienced by mothers in the last twelve months, together with their pregnancy outcomes over the same period, we estimate:

$$
C_{i j s t}^{\text {StillBir }}=\beta_{0}^{\text {StillBir,l }}+\beta_{1}^{\text {StillBir,l }, V i o R e c e n t}{ }_{i j s}^{l}+X_{i j t}^{\prime} \beta_{3}^{\text {StillBir }, l}+\gamma_{s}+\tau_{t}+\sigma_{j \times t}+\eta_{r}+\epsilon_{i j s t}^{s b, l} .
$$

Here, $C_{i j s t}^{\text {StillBir }}$ is an indicator for whether a pregnancy resulted in stillbirth. In all other respects, equation (3) is identical to equation (2a). As in earlier analysis, we cluster standard errors at the country level, and, since there are only twenty two clusters in this specification, we also compute wild bootstrap p-values.

\subsubsection{Selection on unobservables}

Estimation of equations (1) and (2a) show the association between domestic violence and mortality, once we condition on observable confounding factors which may lead to selection into violence and which may also affect mortality. A potential concern might be that unobserved selection into

\footnotetext{
${ }^{19}$ More specifically, the beginning of the calendar is five calendar years prior to the year of first interview in the survey. The calendar period for an individual woman is then all months up to the month of interview in the year of interview, plus the five (six) calendar years preceding the year of interview if the interview spans one (two) years.

${ }^{20}$ As a robustness check, we also consider the relationship between violence and loss at any month gestation.
} 
violence drives our estimated effects. For instance, we cannot rule out that socio-economic status (and/or unobservable family background variables) are different across violence victims and nonvictims. Since such unobservables are also likely to be negatively correlated with child mortality, our estimate of the treatment effect of interest $\beta_{1}$ will be biased away from zero. ${ }^{21}$ To investigate further the degree to which unobserved selection into violence may account for our associations net of observable confounding factors, we use methods described in Altonji et al. (2005) and Oster (2019) to investigate whether there is evidence that our observed conditional associations are driven entirely by unobserved selection. We do this for the full sample, and for a sub-sample in which we have information on additional pre-determined confounders (height and religion) and investigate the sensitivity of our estimates to their inclusion.

Altonji, Elder, Taber ratios: We follow the procedure introduced in Altonji et al. (2005) (hereafter, AET) to assess how much stronger selection on unobservables would need to be, relative to selection on observables, to fully explain away our estimated effects. ${ }^{22}$ We first estimate a regression in which we include a restricted number of controls. This gives us our estimate of the treatment effect $\beta_{1}^{R}$. Next, we add in our full set of pre-determined controls. From this, we obtain our estimate of the treatment effect $\beta_{1}^{F}$. The AET ratio is then calculated as:

$$
\frac{\beta_{1}^{F}}{\beta_{1}^{R}-\beta_{1}^{F}} .
$$

The larger the value of this ratio, the larger selection on unobservables would need to be in order to completely explain away the estimated effect of domestic violence on child mortality that we find. The intuition behind this calculation is that selection on unobservables will need to be high to explain our effect away, the higher is our estimate of $\beta_{1}^{F}$ (the numerator), and the smaller the difference between our estimated $\beta_{1}$ with and without controls, $\beta_{1}^{R}-\beta_{1}^{F}$ (the denominator).

Oster (2019) $\delta$ and $\beta_{1}^{*}$ statistics: Oster (2019) extends the work on selection on unobservables in Altonji et al. (2005), arguing that omitted variable bias is proportional to coefficient movements only if these movements are scaled by movements in the R-squared from the regression. She develops both a consistent estimator for bias-adjusted treatment effects $\left(\beta_{1}^{*}\right)$ as well as an estimate of how

\footnotetext{
${ }^{21}$ This reasoning assumes no correlation between violence and other observables.

${ }^{22}$ This methodology has been employed in a number of contexts in the economics literature, including Nunn and Wantchekon (2011), Satyanath et al. (2017), and Arthi and Fenske (2018).
} 
much selection on unobservables relative to selection on observables $(\delta)$ would be needed in order for there to be no treatment effect $\left(\beta_{1}=0\right)$.

We assess the potential magnitude of omitted variable bias using the procedure outlined in Oster (2019). We first assume equal selection on unobservable variables as observable variables (i.e. $\delta=1$ ), and calculate a lower bound on our main effects $\left(\beta_{1}^{*}\right)$. We also calculate how large selection on unobservables would need to be, relative to selection on observables, in order for our estimated effects to be zero. ${ }^{23}$

\section{Results}

Estimates of the impact of physical violence only and sexual violence only are summarized in Table 1 from estimation of equation (1) and Table 2 from estimation of equation (2a) and (2b). These estimates provide evidence of a consistent positive association between domestic violence faced by the mother and child mortality. ${ }^{24}$

\subsection{Estimated associations adjusting for observable factors}

\subsubsection{Violence ever experienced}

Children born to mothers who are victims of physical domestic violence are 0.4 percentage points more likely to die within the first month of being born compared to children born to mothers who are not victims (panel A, Column (IV), Table 1). The estimated association for sexual violence is smaller, suggesting that children born to mothers who are victims of sexual violence are 0.2 percentage points more likely to die within the first month of being born. These estimates are statistically significant, when using both conventional cluster-robust standard errors and when computing more conservative wild cluster bootstrap p-values. ${ }^{25}$

We find similar results when considering infant (under-5) mortality, with children born to moth-

\footnotetext{
${ }^{23}$ A choice parameter in this exercise is $R^{\max }$, which is the hypothetical $R^{2}$ from a regression on both observed and unobserved controls; this is generally less than 1 , given measurement error in the dependent variable, which is likely to be present since mortality here is subject to recall error, and if there is idiosyncratic variation in the dependent variable. Using randomised data, Oster (2019) suggests a sufficient value of $R^{\max }=1.3 \times \tilde{R}^{2}$ where $\tilde{R}^{2}$ is the $R^{2}$ from the regression with full controls. In practice, we use the highest value of $R^{2}$ obtained in our analysis.

${ }^{24}$ While we use linear probability models, just $0.80-2.03 \%$ of predictions when estimating equation (1) are outside of the $[0,1]$ range and $7-7.65 \%$ of predictions when estimating equation $(2 \mathrm{a})$ are outside of the $[0,1]$ range. Our results are robust to instead using probit analysis. Results available on request.

${ }^{25}$ The number of observations drops when we include our vector of controls $X_{i j t}$ due principally to missing observations on spousal characteristics (i.e. age and education).
} 
ers who are victims of domestic physical violence being 0.7 (1.0) percentage points more likely to die within the first year (five years) of being born compared to similar children born to mothers who are not victims (panels B and C, Column (IV), Table 1). Coefficients are larger for physical versus sexual violence, and they are statistically significant regardless of the method used to compute the associated p-value (i.e., conventional cluster-robust standard errors vs. wild cluster bootstrap).

The magnitude of the estimates associations we find are sizeable given that the incidence of neonatal mortality is just $3.2 \%$, infant mortality $6.6 \%$ and under five mortality $9.7 \%$ for all children in our estimation sample.

The literature on leading causes of under-5 mortality suggests that the majority of deaths $(54.1 \%)$ occur in the neonatal period, primarily due to pre-term birth, congenital defects and intrapartum events, whilst in the post-neonatal period leading causes are pneumonia and diarrhoea (Liu et al., 2016). There are several mechanisms which could be driving the relationship between domestic violence and child mortality. If the violence occurs while the mother is pregnant, then an unborn child's health could be directly affected due to blunt physical trauma to the foetus (Nasir and Hyder, 2003). Indirect (and negative) effects could arise due to victims having inadequate access to pre-natal health care, inadequate nutrition and/or victims engaging in risky behaviors as well as experiencing high levels of psychological stress (Yount et al., 2011), which are associated with low birth weight and pre-term delivery, in turn risk factors for increased child mortality (Newberger et al., 1992). Evidence also suggests that women suffering intimate partner violence are less likely to seek preventative health counselling during prenatal care (Petersen et al., 2001). In section 6, we investigate the potential mechanisms underlying our results in more detail.

\subsubsection{Violence experienced in the last twelve months}

Table 2 provides estimates for the relationship between domestic violence experienced in the last twelve months by the mother and neonatal mortality. We are now restricted to studying neonatal mortality since this is the only mortality measure that children have been fully exposed to in the last twelve months. Considering births only occurring in the twelve months prior to the survey leads to a considerably reduced sample size. For example, in the physical violence regressions the sample falls from 1.1 million to around 45,000 upon inclusion of a full set of controls.

We find similar sized associations for physical violence experienced in the last twelve months 
as violence ever experienced. Exposure to physical violence in the last twelve months is positively associated with an increase in the probability of neonatal mortality of 0.4 percentage points (Column (IV), Panel A, Table 2). This association is sizeable given that the incidence of neonatal mortality in this sample is $2.4 \%$. However, wild bootstrap p-values suggest that, once region and year fixed effects are accounted for, estimates are no longer statistically significant. Thus, whilst the coefficient point estimate is the same as in our ever experienced violence regressions, the standard error is much larger. Since this estimate relies on within-region and year of birth variation, it may be that despite the apparently large sample size, we do not have enough within region and year variation in this reduced sample to precisely identify these associations. We do not find any statistically significant conditional associations of recent sexual violence on neonatal mortality, using either conventional standard errors or the wild bootstrap. This may reflect the fact that prevalence rates of sexual violence are much lower than physical violence (Figure A3), lowering the predictive power when considering associations of this type of violence.

Equation (2a) exploits information on timing of abuse to consider the association of violence experienced in the last twelve months withn neonatal mortality. As a check on our results, we construct a placebo regression in which we drop women who experienced violence in the last twelve months, and instead assign 'treatment' (violence) to women who reported ever experiencing violence, but not in the last twelve months. We therefore investigate whether historical experience of violence predicts neonatal mortality in the last twelve months. Historical experience of violence fails to predict recent neonatal mortality, in any of our specifications (Table A5). For physical violence, our estimates are striking, in that they are very small and close to zero. This is mirrored in our estimate for any violence, which is approximately zero. Overall, for these outcomes, the placebo analysis suggests that our estimates for recent violence, as given from estimation of equation (2a), are not due to unobserved confounders correlated with experience of violence. For sexual violence, placebo estimates are of similar magnitude and continue to be statistically insignificant, with much larger p-values. Overall, the evidence for sexual violence is less compelling but nonetheless does not suggest a role of historical sexual violence on recent neonatal mortality.

Turning our attention to frequency of violence, our measure of severity of violence that a woman experiences, we again tend to find imprecise associations, but find some (weak) evidence that frequency of physical violence matters. Exposure to frequent physical violence in the last twelve months 
is positively associated with an increase in the probability of neonatal mortality by 0.7 percentage points, and this is statistically significant at the $10 \%$ level when using both conventional standard errors and wild bootstrap p-values (Column (IV), Panel B, Table 2). This magnitude is twice the magnitude found for sometimes experiencing physical violence, which is 0.3 percentage points, but not statistically significant.

\section{$5 \quad$ Investigating mortality selection and selection on unobservables}

In this section we first investigate whether there is evidence of mortality selection, or survivorship bias. We then investigate the role of selection into violence on unobservables.

\subsection{Mortality selection}

Table 3 shows the association between violence experienced in the last twelve months and stillbirth. We find that pregnancies of mothers who are victims of physical domestic violence are 1.4 percentage points more likely to end in stillbirth than pregnancies of women who are not victims (Column (IV), Table 3). A similar picture emerges for sexual violence. This association is sizable given the rate of stillbirth in our sample is $3.34 \%$. Thus, our estimates suggest that significant loss of life has already occurred before children are born, so that our estimates of mortality based on live births underestimate the true magnitude of the effect of domestic violence on offspring mortality.

Though we do not focus on this in our main analysis, we do consider the association between violence and loss at any gestations (Table A6). The estimated magnitudes are larger, reflecting the higher frequency of pregnancy loss at any gestation (16.2\% of pregnancies) compared to stillbirth. We also see that estimated magnitudes are larger for sexual violence. This may indicate potential behavioural effects. Since our measure of loss here also includes induced abortions, this would be consistent with the notion that induced abortions may increase when a woman experiences sexual violence, though we acknowledge that this is speculative.

\subsection{Selection on unobservables}

We investigate potential selection on unobservables using the procedure outlined in Altonji et al. (2005) and Oster (2019) to construct a lower bound on our estimates, as described in section 3.2.2. ${ }^{26}$

\footnotetext{
${ }^{26}$ Means of additional control variables across victims and non-victims are given in Table A2.
} 
We do this first for our full sample with all controls, and then for smaller samples for which additional pre-determined variables are available. These pre-determined variables are height of the mother, and religion.

Table 4 reports estimated coefficients on domestic physical violence ever experienced by the mother for different child mortality outcomes, while Table 5 gives estimated coefficients on sexual violence ever experienced by the mother. ${ }^{27}$ These Tables display coefficients on domestic violence with no controls ( $\beta_{1}^{R}$; column (I), Tables 4 and 5 ), as well as with all controls ( $\beta_{1}^{F}$, column (II), Tables 4 and 5). We further show the estimate of the AET ratio, the lower bound treatment effect $\left(\beta_{1}^{*}\right)$ and the null effect selection ratio $(\delta)$ for all regression specifications with different violence measures and child mortality outcomes. Assuming equal selection on unobservables as observables, our estimates of the effect of violence on mortality are attenuated but nonetheless continue to suggest a positive effect. Our estimates for the effect of physical violence are most robust, with a lower bound between $75-80 \%$ of our estimated effects with full controls. The estimates for sexual violence decline in some cases (but not all) by around $50 \%$, but are still positive and economically meaningful. Our estimate of $\delta$ suggests that selection on unobservables would need to be $2-6$ times that of selection on observables to explain away our estimated effect of violence on child mortality. For physical violence, the AET ratios range from 2.45 to 3.22 , whilst for sexual violence they range from 0.93 to 4.77 , suggesting the effect of sexual violence on mortality (and in particular infant mortality) is more sensitive to selection on unobservables than the effect of physical violence on mortality, or indeed sexual violence on neonatal or under-5 mortality.

In column (III) we add maternal height to the control set. We investigate the inclusion of maternal height since this is a measure of the mother's overall stock of health, is considered a useful summary measure of biological wellbeing (Komlos and Baur, 2004; Garcia and Quintana-Domeque, 2007), a permanent measure of health (Strauss and Thomas, 2008; Bozzoli et al., 2009) and is pre-determined. ${ }^{28}$ Height is therefore preferable to more transitory measures of mother's health such as BMI and in previous studies it has been shown to be related to child mortality (Monden and Smits, 2009; Bhalotra and Rawlings, 2011, 2013). We do not control for height in our main

\footnotetext{
${ }^{27}$ Table A7 gives coefficients on domestic violence from specifications where violence is physical and sexual violence experienced by the mother in the last twelve months. We find a similar pattern of results, but do not discuss them in depth here due to space considerations.

${ }^{28}$ This matters particularly for our estimates of the impact of violence ever experienced since in these estimations we are considering births that may have occurred many years previously.
} 
analysis since information on height of mothers was not collected in 16 of the 54 surveys that make up our sample (see Table A1); our sample size for under-5 mortality outcomes and physical violence ever experienced falls from 1.1 million to 857,000 (panel C, Table 4). Our estimated $\beta_{1}$ and corresponding $\beta_{1}^{*}$ is unchanged when we include maternal height, whilst our values for the AET ratio and for $\delta$ increase - since there appears to be selection on maternal height, and since our estimate is unchanged, selection on unobservables must be higher to explain away the effect of violence on mortality. We continue to find that estimates of AET ratios and $\delta$ suggest the effect of sexual violence on child mortality (in particular on infant and under-5 mortality) is more sensitive to selection on unobservables than the effect of physical violence on child mortality.

In column (IV) we include religion dummies. Religiosity has been shown to be associated with better health amongst men, women, and children, with risky behaviours (smoking, drinking), being lower among religious groups (Deaton, 2009; Chiswick and Mirtcheva, 2013). One possible mechanism underlying differences in child health by religion might be differences in utilisation of prenatal health care and/or child immunisation practices across different religions, reflecting variation in cultural practices (Gyimah et al., 2006; Ha et al., 2014). Information on religion is not collected in 16 out of 54 surveys (see Table A1). ${ }^{29}$ We include dummies for Christian, Muslim, and other religion (the omitted category is "no religion"). Our sample size for under-5 mortality outcomes and physical violence ever experienced falls from 1.1 million to 790,000 (panel C, Table 4). Our estimated coefficients are robust to the inclusion of religion dummies, and estimated coefficients are of similar magnitude. Estimates of $\beta_{1}^{*}$ continue to suggest economically meaningful sized effects, $\delta$ ranges from 6.7 to 8.1 for physical violence ever experienced and from 3.8 to 5.8 for sexual violence ever experienced (across different child mortality outcomes). The AET ratios are also higher.

In our final - most restricted - specification, we include both height and religion dummies (Column (V)). Our sample size for under-5 mortality and physical violence ever experienced falls to 472,000 (panel $\mathrm{C}$, Table 4), and once again estimates of $\beta_{1}$ are broadly similar, $\beta_{1}^{*}$ indicate economically meaningful effects, and $\delta$ are large, lying between 3.42 and 6.35 for physical violence ever experienced and between 3.67 and 7.97 for sexual violence ever experienced. ${ }^{30}$

\footnotetext{
${ }^{29}$ Note that the set of surveys for which we do not have information on religion differs from the set of surveys for which we do not have information on height.

${ }^{30}$ Essentially, the large increase in the AET ratio and $\delta$ reflect the fact that by conditioning on more observables, and given small movements in the point estimate of $\beta_{1}$, the role of unobservables would need to be even larger to explain away the effect of domestic violence on child mortality than that estimated without these controls.
} 


\section{$6 \quad$ Investigating potential mechanisms}

There may be a number of potential mechanisms that drive the observed associations estimated in section 4 . To investigate whether such variables mediate the relationship, we estimate associations between domestic violence and pathways of interest. We estimate the following equations:

$$
Y_{i j s t}=\beta_{0}^{l}+\beta_{1}^{l} V_{i j s}^{l}+X_{i j t}^{\prime} \beta_{3}^{l}+\gamma_{s}+\tau_{t}+\sigma_{j \times t}+\eta_{r}+\epsilon_{i j s t}^{l},
$$

where $Y_{i j s t}$ is our mediator of interest. We focus on a number of potential pathways which may mediate the relationship: maternal health, risk behaviours, prenatal care, and feeding practices (Yount et al., 2011). These are captured by an indicator for anemia, mother's BMI, an indicator for whether the mother smokes, indicators for antenatal care (any antenatal appointments, and more than four - the minimum recommended by the World Health Organisation WHO, 2016), and breastfeeding indicators (whether the child was ever breastfed, whether the child was breastfed within 1 day, and within 1 hour of birth). Whilst a number of other potential mediators exist, such as the direct effect of biological stress responses, and indirect effects through risky behaviours such as alcohol and drug use, psychosocial care, nutrition and other aspects of infant care, we do not investigate these pathways since information on these pathways is not collected in the DHS. Also, information on pre- and postnatal care is available only for recent births, so for these variables our sample is considerably smaller than in the main analysis. In all other respects, equation (4) mirrors equation (1) estimated earlier.

We observe strong associations between physical violence and almost all potential mediators, with the exception of anemia. Physical violence ever experienced is associated with lower BMI, a greater propensity to smoke, fewer antenatal appointments, a reduced propensity to birth in hospital, and lower incidence of breastfeeding (Table 6). In what follows, we focus on physical violence ever experienced, but note that our results for sexual violence ever experienced (Table 7) lead to similar conclusions. ${ }^{31}$

When we consider smoking and breastfeeding, estimated associations are robust to the inclusion

\footnotetext{
${ }^{31}$ Though we do not report them in the paper, we also considered recent violence, and found similar conclusions, though our estimates for some outcomes are more imprecise, suggesting that the smaller sample limits the degree to which we can make inferences on the relationship. Results available on request.
} 
of additional control variables, with similar, or in some cases larger, estimates once we condition on $X_{i j t}$. Women who ever experienced physical violence are 3.0 percentage points more likely to smoke (compared to a smoking rate in the sample of $4.90 \%$ in the sample). This is important since smoking in pregnancy is associated with increased risk of low birth weight and neonatal mortality (Ananth and Platt, 2004) as well as death in the post-neonatal period (Hofvendahl, 1995). Maternal smoking has also been linked to respiratory diseases such as pneumonia (Le Roux et al., 2015; Nguyen et al., 2017), a leading cause of death in children under the age of 5 (Liu et al., 2016).

Effects of violence on breastfeeding are of a smaller magnitude, both in absolute and relative terms; the association between violence and ever breastfeeding is just 0.2 percentage point reduction (with a mean rate of $96.2 \%$ ). Women who ever experienced physical violence are 2.9 percentage points less likely to initiate breastfeeding within one hour of birth and 2.0 percentage points less likely to initiate breastfeeding within one day (compared to an incidence of $65 \%$ and $85.1 \%$ in the sample). Despite this, the effects on breastfeeding are of particular interest since delayed initiation of breastfeeding has been shown to increase neonatal mortality (Edmond et al., 2006), and longer breastfeeding duration is associated with lower pneumonia related mortality (Nguyen et al., 2017). The AET ratios and $\delta$ for smoking and breastfeeding variables are large, suggesting that selection on unobservables would need to be large to explain away the estimated effect, and estimates of $\beta_{1}^{*}$ continue to suggest large effects of violence on these outcomes. Thus, we find some evidence that violence affects smoking behaviour and breastfeeding initiation, and that these associations are not likely to be explained by unobserved selection into violence.

In the case of BMI, antenatal appointments, and hospital births, estimated associations are sensitive to conditioning on our set of controls, suggesting that selection into violence may play an important role in the observed associations. This is borne out by the estimated AET ratios and $\delta$, which are less than one for many of these specifications, suggesting that selection on unobservables would need to be less than selection on observables to explain away the estimated effects we find. The lower bound for our estimate, $\beta_{1}^{*}$, in these cases is considerably lower than the estimated effects. Thus, it would appear that mother's health or prenatal inputs are more likely to be driven by unobservable characteristics than by violence itself, suggesting these channels are not potential pathways through which violence affects mortality. 


\section{Discussion and Conclusion}

This paper provides evidence of a strong positive association between domestic violence experienced by mothers on the subsequent mortality of their children in a large sample of developing countries, where up to $60 \%$ of ever partnered women have suffered domestic violence. We are able to utilize comparable data on children born between 1966 and 2016 from across thirty two different developing countries to examine this relationship.

We find statistically significant and sizeable correlations between domestic violence ever experienced by the mother on her children's mortality outcomes. Children born to mothers who were victims of physical domestic violence are $0.4,0.7$ and 1.0 percentage points more likely to die within thirty days, a year and the first five years of being born compared to similar children born to mothers who were never victims. We find similar associations between violence experienced in the last twelve months and neonatal mortality, with suggestive evidence of a dose-response relationship; more frequent violence is associated with a larger increase in mortality. We find evidence that violence is also associated with pregnancy loss, suggesting that mortality selection may affect our estimates based on live births. Investigating selection on unobservables suggests a limited role for unobservables in driving the observed relationship, particularly for physical violence. Investigating mechanisms, we find that selection into violence explains much of the association between violence and maternal health and between violence and prenatal behaviours, but not between violence and maternal smoking or between violence and breastfeeding initiation. We therefore posit that maternal smoking and breastfeeding initiation may be potential mediators for our observed relationship between domestic violence and child mortality. Our findings may suggest that stress caused by exposure to domestic violence may increase the likelihood of smoking, and reduce the likelihood of breastfeeding, via both behavioural and biological responses (Richards et al., 2011; Dozier et al., 2012; Doulougeri et al., 2013). While speculative, we consider this an important avenue for future research. 


\section{References}

Agüero, J.M., Frisancho, V., 2018. Misreporting of Intimate Partner Violence in Developing Countries: Measurement Error and New Strategies to Minimize it. Technical Report. Mimeo, University of Connecticut.

Aizer, A., 2011. Poverty, violence and health. Journal of Human Resources 46, 518-538.

Altonji, J., Elder, T., Taber, C., 2005. Selection on observed and unobserved variables: Assessing the effectiveness of catholic schools. Journal of Political Economy , 151-184.

Ananth, C.V., Platt, R.W., 2004. Reexamining the effects of gestational age, fetal growth, and maternal smoking on neonatal mortality. BMC pregnancy and childbirth 4, 22.

Arthi, V., Fenske, J., 2018. Polygamy and child mortality: Historical and modern evidence from nigeria?s igbo. Review of Economics of the Household 16, 97-141.

Bhalotra, S., Rawlings, S.B., 2011. Intergenerational persistence in health in developing countries: The penalty of gender inequality? Journal of Public Economics 95, 286-299.

Bhalotra, S., Rawlings, S.B., 2013. Gradients of the intergenerational transmission of health in developing countries. Review of Economics and Statistics 95, 660-672.

Black, M., Basile, K., Breiding, M., Smith, S., Walters, M., Merrick, M., Chen, J., Stevens, M., 2011. National intimate partner and sexual violence survey: 2010 summary report .

Bozzoli, C., Deaton, A., Quintana-Domeque, C., 2009. Adult height and childhood disease. Demography $46,647-669$.

Cameron, A.C., Gelbach, J.B., Miller, D.L., 2008. Bootstrap-based improvements for inference with clustered errors. The Review of Economics and Statistics 90, 414-427.

Chai, J., Fink, G., Kaaya, S., Danaei, G., Fawzi, W., Ezzati, M., Lienert, J., Fawzi, M.C.S., 2016. Association between intimate partner violence and poor child growth: results from 42 demographic and health surveys. Bulletin of the World Health Organization 94, 331. 
Chiswick, B.R., Mirtcheva, D.M., 2013. Religion and child health: Religious affiliation, importance, and attendance and health status among american youth. Journal of family and economic issues $34,120-140$.

Currie, J., Mueller-Smith, M., Rossin-Slater, M., 2018. Violence while in Utero: The Impact of Assaults During Pregnancy on Birth Outcomes. Working Paper 24802. National Bureau of Economic Research. URL: http://www.nber.org/papers/w24802, doi:10.3386/w24802.

Deaton, A.S., 2009. Aging, religion, and health. Technical Report. NBER Working Paper No. 15271.

Devries, K., Mak, J., Garcia-Moreno, C., Petzold, M., Child, J., Falder, G., Lim, S., Bacchus, L., Engell, R., Rosenfeld, L., Pallitto, C., Vos, T., Abrahams, N., Watts, C., 2013. The global prevalence of intimate partner violence against women. Science 340, 1527-1528.

Doulougeri, K., Panagopoulou, E., Montgomery, A., 2013. The impact of maternal stress on initiation and establishment of breastfeeding. Journal of Neonatal Nursing 19, 162-167.

Dozier, A.M., Nelson, A., Brownell, E., 2012. The relationship between life stress and breastfeeding outcomes among low-income mothers. Advances in preventive medicine 2012.

Edmond, K.M., Zandoh, C., Quigley, M.A., Amenga-Etego, S., Owusu-Agyei, S., Kirkwood, B.R., 2006. Delayed breastfeeding initiation increases risk of neonatal mortality. Pediatrics 117, e380e386.

Erten, B., Keskin, P., 2018. For better or for worse?: Education and the prevalence of domestic violence in turkey. American Economic Journal: Applied Economics 10, 64-105.

Garcia, J., Quintana-Domeque, C., 2007. The evolution of adult height in europe: a brief note. Economics \& Human Biology 5, 340-349.

Gyimah, S.O., Takyi, B.K., Addai, I., 2006. Challenges to the reproductive-health needs of african women: on religion and maternal health utilization in ghana. Social science \& medicine 62 , $2930-2944$.

Ha, W., Salama, P., Gwavuya, S., Kanjala, C., 2014. Is religion the forgotten variable in maternal and child health? evidence from zimbabwe. Social science \& medicine 118, 80-88. 
Hofvendahl, E.A., 1995. Smoking in pregnancy as a risk factor for long-term mortality in the offspring. Paediatric and perinatal epidemiology 9, 381-390.

Kishor, S., Johnson, K., 2004a. Profiling domestic violence: a multi-country study. .

Kishor, S., Johnson, K., 2004b. Profiling domestic violence: A multi-country study. Calverton, Maryland: ORC Macro.

Kling, J.R., Liebman, J.B., Katz, L.F., 2007. Experimental analysis of neighborhood effects. Econometrica $75,83-119$.

Komlos, J., Baur, M., 2004. From the tallest to (one of) the fattest: the enigmatic fate of the american population in the 20th century. Economics \& Human Biology 2, 57-74.

Le Roux, D.M., Myer, L., Nicol, M.P., Zar, H.J., 2015. Incidence and severity of childhood pneumonia in the first year of life in a south african birth cohort: the drakenstein child health study. The Lancet Global Health 3, e95-e103.

Liu, L., Oza, S., Hogan, D., Chu, Y., Perin, J., Zhu, J., Lawn, J.E., Cousens, S., Mathers, C., Black, R.E., 2016. Global, regional, and national causes of under-5 mortality in 2000-15: an updated systematic analysis with implications for the sustainable development goals. The Lancet 388, $3027-3035$.

MacKinnon, J.G., 2019. How cluster-robust inference is changing applied econometrics. Canadian Journal of Economics/Revue canadienne d'économique .

MacKinnon, J.G., Webb, M.D., 2017. Wild bootstrap inference for wildly different cluster sizes. Journal of Applied Econometrics 32, 233-254.

Monden, C.W., Smits, J., 2009. Maternal height and child mortality in 42 developing countries. American Journal of Human Biology 21, 305-311.

Nasir, K., Hyder, A.A., 2003. Violence against pregnant women in developing countries: review of evidence. The European Journal of Public Health 13, 105-107.

Newberger, E., Barkan, S., Lieberman, E., McCormick, M., Kersti, Y., Gary, L., Schechter, S., 1992. Abuse of pregnant women and adverse birth outcome current knowledge and implications for practice. Journal of the American Medical Association 267, 2370-72. 
Nguyen, T., Tran, T., Roberts, C., Fox, G., Graham, S., Marais, B., 2017. Risk factors for child pneumonia-focus on the western pacific region. Paediatric respiratory reviews $21,95-101$.

Nunn, N., Wantchekon, L., 2011. The slave trade and the origins of mistrust in africa. American Economic Review 101, 3221-52.

Oster, E., 2019. Unobservable selection and coefficient stability: Theory and evidence. Journal of Business \& Economic Statistics 37, 187-204.

Petersen, R., Connelly, A., Martin, S.L., Kupper, L.L., 2001. Preventive counseling during prenatal care: Pregnancy risk assessment monitoring system (prams). American Journal of Preventive Medicine 20, 245-250.

Richards, J.M., Stipelman, B.A., Bornovalova, M.A., Daughters, S.B., Sinha, R., Lejuez, C., 2011. Biological mechanisms underlying the relationship between stress and smoking: state of the science and directions for future work. Biological psychology 88, 1-12.

Satyanath, S., Voigtländer, N., Voth, H.J., 2017. Bowling for fascism: Social capital and the rise of the nazi party. Journal of Political Economy 125, 478-526.

Silverman, J., Decker, M., Reed, E., Raj, A., 2006. Intimate partner violence victimization prior to and during pregnancy among women residing in the 26 United States: Associations with maternal and neonatal health. American Journal of Obstetrics and Gynecology 195, 140-48.

Straus, M.A., 1979. Measuring intrafamily conflict and violence: The conflict tactics (CT) scales. Journal of Marriage and Family 41, 75-88.

Strauss, J., Thomas, D., 2008. Health over the life course, in: Schultz, T.P., Strauss, J.A. (Eds.), Handbook of Development Economics. Elsevier. volume 4, pp. 3375-3474.

WHO, 2016. WHO recommendations on antenatal care for a positive pregnancy experience. World Health Organization.

Yount, K., DiGirolamo, A., Ramakrishnan, U., 2011. Impacts of domestic violence on child growth and nutrition: A conceptual review of the pathways of influence. Social Science and Medicine 72, $1534-1554$. 


\section{Figures and Tables}

\section{Figure 1}

Child mortality across victims and non-victims of domestic violence, where violence is ever experienced by the mother

(a) Neonatal Mortality

(b) Infant Mortality
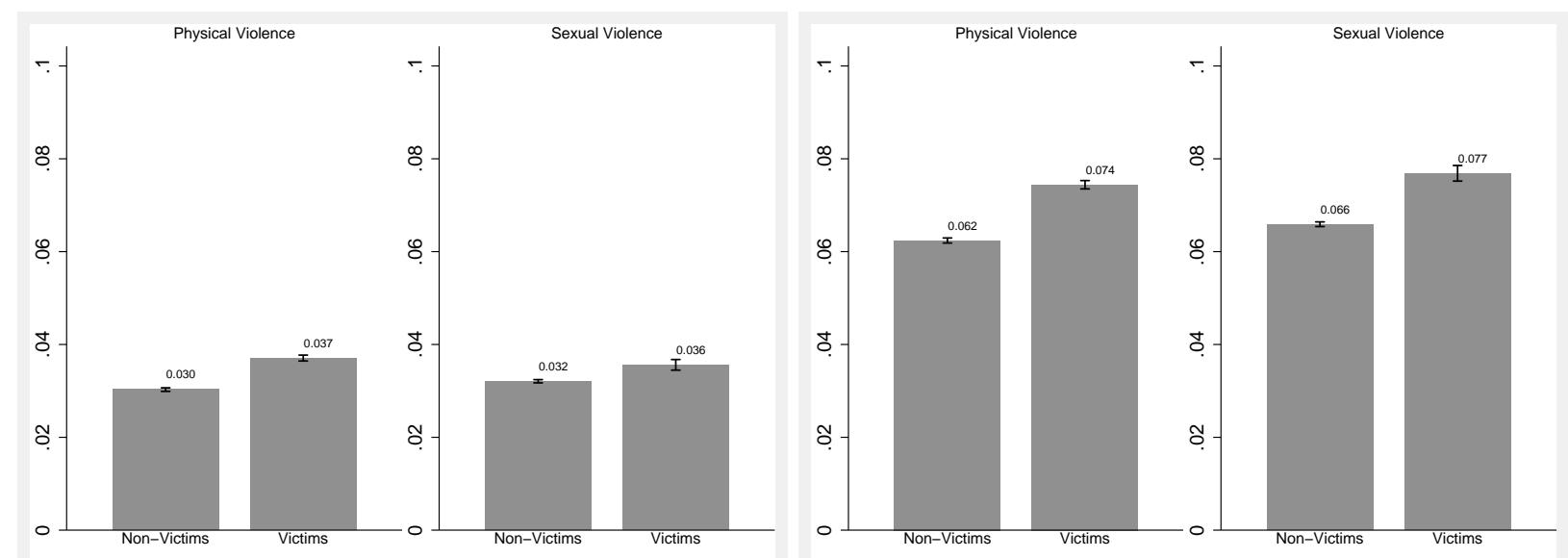

(c) Under-5 Mortality

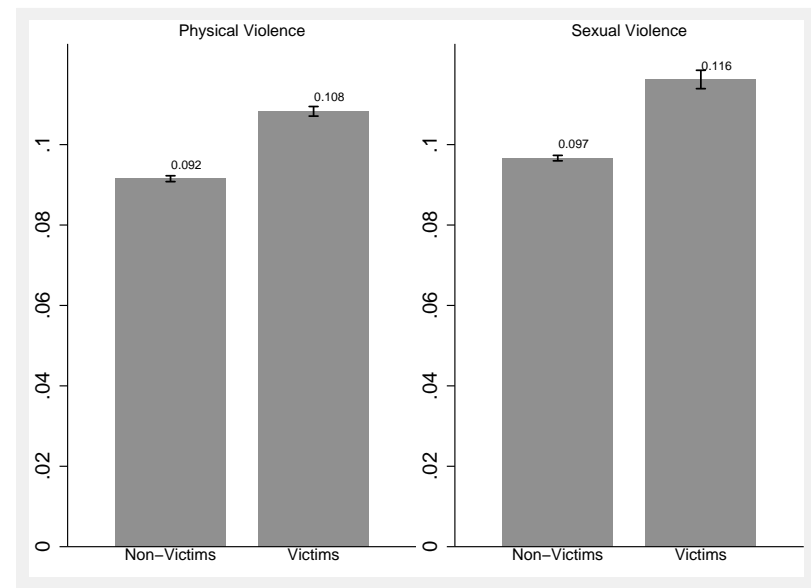

Notes: Neonatal, infant, and under-5 mortality is measured as the fraction of children dying within one month, one year, and five years of being born. Inclusion in the neonatal, infant, and under-5 mortality sample is conditional upon the child being born at least one month, one year, and five years ago.

Source: Data from the Demographic and Health Surveys. See Table A1 for the surveys used. 
Figure 2

Neonatal mortality across victims and non-victims of domestic violence, where violence is experienced by the mother in the last 12 months

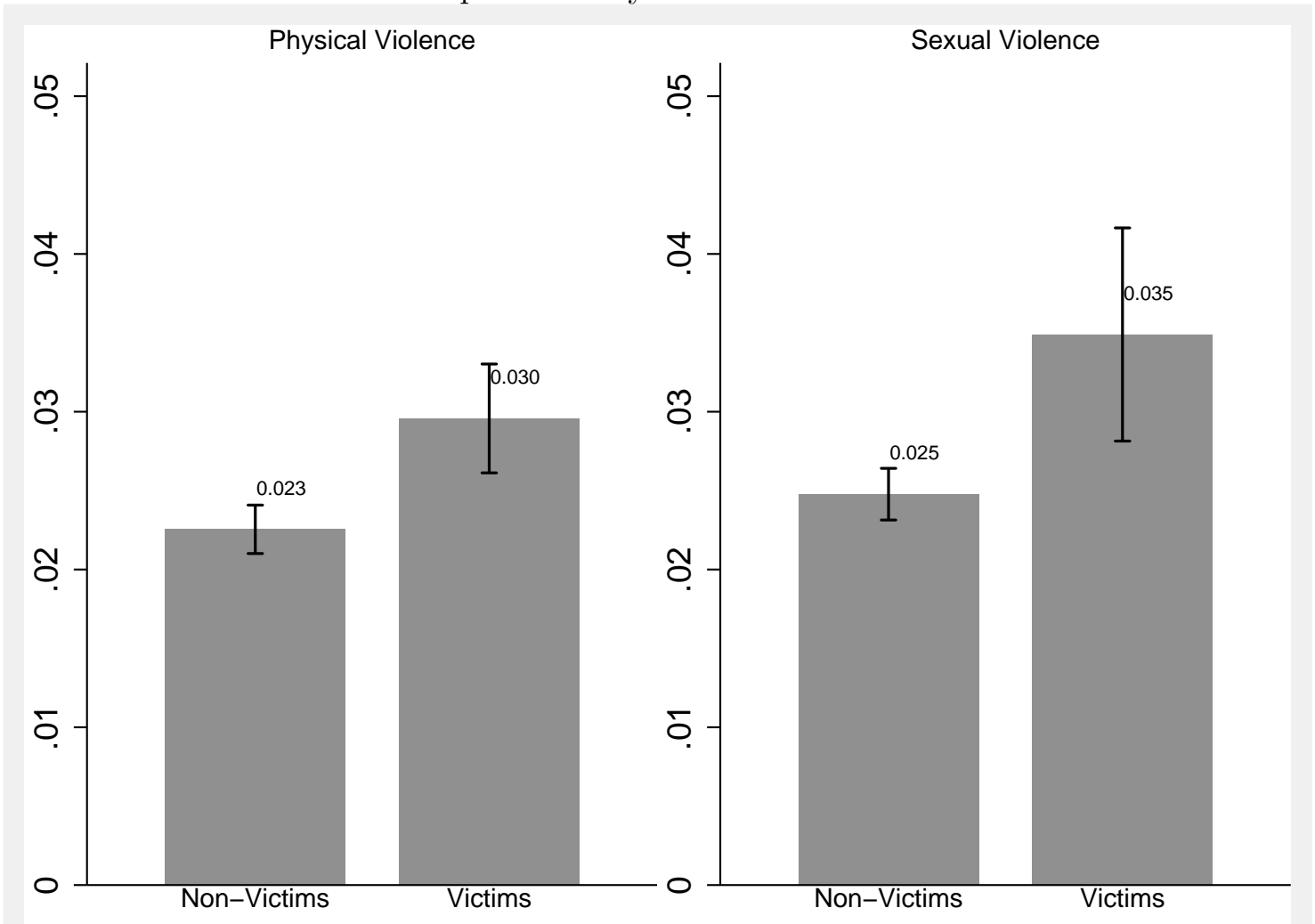

Notes: Neonatal mortality is measured as the fraction of children dying within one month. Inclusion in the sample is conditional upon the child being born in the last 12 months, and at least one month ago, relative to date of interview. Source: Data from the Demographic and Health Surveys. See Table A1 for the surveys used. 


\section{TABLE 1}

Associations of child mortality with domestic violence, where violence is ever experienced by the mother

\begin{tabular}{|c|c|c|c|c|}
\hline & (I) & (II) & (III) & $(\mathrm{IV})$ \\
\hline \multicolumn{5}{|c|}{ A: Dependent variable $=$ Neonatal mortality } \\
\hline Physical Violence & $\begin{array}{c}0.005^{*} \\
(0.003)\end{array}$ & $\begin{array}{l}0.006^{* * *} \\
(0.002)\end{array}$ & $\begin{array}{l}0.004^{* * *} \\
(0.001)\end{array}$ & $\begin{array}{l}0.004^{* * *} \\
(0.001)\end{array}$ \\
\hline wild bootstrap p-value & {$[0.070]$} & {$[0.000]$} & {$[0.000]$} & {$[0.000]$} \\
\hline Observations & 1468782 & 1139349 & 1139349 & 1139349 \\
\hline$R^{2}$ & 0.000 & 0.004 & 0.010 & 0.012 \\
\hline$N_{\text {clust }}$ & 32 & 32 & 32 & 32 \\
\hline Sexual Violence & $\begin{array}{c}0.002^{* *} \\
(0.001)\end{array}$ & $\begin{array}{l}0.003^{* * *} \\
(0.001)\end{array}$ & $\begin{array}{l}0.002^{* *} \\
(0.001)\end{array}$ & $\begin{array}{l}0.002^{* *} \\
(0.001)\end{array}$ \\
\hline wild bootstrap p-value & {$[0.063]$} & {$[0.011]$} & {$[0.088]$} & {$[0.064]$} \\
\hline Observations & 1401840 & 1078495 & 1078495 & 1078495 \\
\hline$R^{2}$ & 0.000 & 0.004 & 0.010 & 0.012 \\
\hline$N_{\text {clust }}$ & 29 & 29 & 29 & 29 \\
\hline \multicolumn{5}{|c|}{ B: Dependent variable $=$ Infant Mortality } \\
\hline Physical Violence & $\begin{array}{c}0.010^{* *} \\
(0.005)\end{array}$ & $\begin{array}{l}0.009^{* * *} \\
(0.002)\end{array}$ & $\begin{array}{l}0.007^{* * *} \\
(0.001)\end{array}$ & $\begin{array}{l}0.007^{* * *} \\
(0.001)\end{array}$ \\
\hline wild bootstrap p-value & {$[0.068]$} & {$[0.001]$} & {$[0.000]$} & {$[0.000]$} \\
\hline Observations & 1403839 & 1086978 & 1086978 & 1086978 \\
\hline$R^{2}$ & 0.000 & 0.012 & 0.026 & 0.029 \\
\hline$N_{\text {clust }}$ & 32 & 32 & 32 & 32 \\
\hline Sexual Violence & $\begin{array}{l}0.009^{* * * *} \\
(0.003)\end{array}$ & $\begin{array}{l}0.008^{* * *} \\
(0.002)\end{array}$ & $\begin{array}{c}0.004^{* *} \\
(0.001)\end{array}$ & $\begin{array}{l}0.004^{* * * *} \\
(0.001)\end{array}$ \\
\hline wild bootstrap p-value & {$[0.022]$} & {$[0.007]$} & {$[0.051]$} & {$[0.034]$} \\
\hline Observations & 1339687 & 1028695 & 1028695 & 1028695 \\
\hline$R^{2}$ & 0.000 & 0.011 & 0.025 & 0.029 \\
\hline$N_{\text {clust }}$ & 29 & 29 & 29 & 29 \\
\hline \multicolumn{5}{|c|}{ C: Dependent variable $=$ Under-5 Mortality } \\
\hline Physical Violence & $\begin{array}{c}0.013^{*} \\
(0.007)\end{array}$ & $\begin{array}{l}0.012^{* * *} \\
(0.003)\end{array}$ & $\begin{array}{l}0.010^{* * *} \\
(0.002)\end{array}$ & $\begin{array}{l}0.010^{* * *} \\
(0.002)\end{array}$ \\
\hline wild bootstrap p-value & {$[0.152]$} & {$[0.005]$} & {$[0.000]$} & {$[0.000]$} \\
\hline Observations & 1118738 & 857086 & 857086 & 857086 \\
\hline$R^{2}$ & 0.000 & 0.023 & 0.050 & 0.054 \\
\hline$N_{\text {clust }}$ & 32 & 32 & 32 & 32 \\
\hline Sexual Violence & $\begin{array}{c}0.015^{* *} \\
(0.006)\end{array}$ & $\begin{array}{l}0.016^{* * *} \\
(0.004)\end{array}$ & $\begin{array}{l}0.007^{* * * *} \\
(0.002)\end{array}$ & $\begin{array}{l}0.008^{* * *} \\
(0.002)\end{array}$ \\
\hline wild bootstrap p-value & {$[0.041]$} & {$[0.006]$} & {$[0.016]$} & {$[0.007]$} \\
\hline Observations & 1067223 & 810515 & 810515 & 810515 \\
\hline$R^{2}$ & 0.000 & 0.022 & 0.049 & 0.053 \\
\hline$N_{\text {clust }}$ & 29 & 29 & 29 & 29 \\
\hline Pre-determined Characteristics $X$ & & $\mathrm{Y}$ & $\mathrm{Y}$ & $\mathrm{Y}$ \\
\hline Survey Year FE & & & $\mathrm{Y}$ & $\mathrm{Y}$ \\
\hline Year of Birth FE & & & $\mathrm{Y}$ & $\mathrm{Y}$ \\
\hline Region FE & & & $\mathrm{Y}$ & $\mathrm{Y}$ \\
\hline Country $\times$ Year of Birth FE & & & & Y \\
\hline
\end{tabular}

Notes: Each cell gives estimates from a separate regression. Regressions follow the specification given in equation (1) which is described in sub-section 3.1. Standard errors are clustered at the country level, and ' $N_{\text {clust }}$ ' refers to the number of clusters in each regression; *** p-value $<1 \%$, ** p-value $<5 \%$, $*$ p-value $<10 \%$. Wild bootstrap p-values are calculated with 9999 repetitions.

Source: Data from the Demographic and Health Surveys. See Table A1 for the surveys used. 


\section{TABLE 2}

Associations of neonatal mortality with domestic violence, where violence is experienced by the mother in the last 12 months

\begin{tabular}{|c|c|c|c|c|}
\hline & (I) & (II) & (III) & $(\mathrm{IV})$ \\
\hline \multicolumn{5}{|c|}{ A: Dependent variable $=$ Neonatal mortality } \\
\hline Physical Violence & $\begin{array}{l}0.007^{* * *} \\
(0.002)\end{array}$ & $\begin{array}{l}0.006^{* * * *} \\
(0.002)\end{array}$ & $\begin{array}{c}0.004^{* *} \\
(0.002)\end{array}$ & $\begin{array}{c}0.004^{*} \\
(0.002)\end{array}$ \\
\hline wildboot p-value & {$[0.006]$} & {$[0.024]$} & {$[0.126]$} & {$[0.149]$} \\
\hline Observations & 56235 & 45183 & 45183 & 45183 \\
\hline$R^{2}$ & 0.000 & 0.002 & 0.014 & 0.015 \\
\hline$N_{\text {clust }}$ & 31 & 31 & 31 & 31 \\
\hline \multirow[t]{2}{*}{ Sexual Violence } & $0.009^{* *}$ & $0.009^{*}$ & 0.007 & 0.007 \\
\hline & $(0.004)$ & $(0.005)$ & $(0.005)$ & $(0.006)$ \\
\hline wildboot p-value & {$[0.092]$} & [0.193] & {$[0.329]$} & {$[0.341]$} \\
\hline Observations & 45185 & 37464 & 37464 & 37464 \\
\hline$R^{2}$ & 0.000 & 0.001 & 0.013 & 0.015 \\
\hline$N_{\text {clust }}$ & 26 & 26 & 26 & 26 \\
\hline \multicolumn{5}{|c|}{ B: Dependent variable $=$ Neonatal mortality } \\
\hline \multirow[t]{2}{*}{ Some Phys. Violence } & $0.007 * * *$ & $0.005^{* *}$ & 0.003 & 0.003 \\
\hline & $(0.003)$ & $(0.002)$ & $(0.002)$ & $(0.002)$ \\
\hline wildboot p-value & {$[0.034]$} & {$[0.039]$} & {$[0.207]$} & {$[0.268]$} \\
\hline \multirow[t]{2}{*}{ Often Phys. Violence } & 0.007 & 0.006 & $0.007 *$ & $0.007^{*}$ \\
\hline & $(0.006)$ & $(0.005)$ & $(0.004)$ & $(0.004)$ \\
\hline wildboot p-value & {$[0.350]$} & {$[0.370]$} & {$[0.096]$} & {$[0.088]$} \\
\hline Observations & 56235 & 45183 & 45183 & 45183 \\
\hline$R^{2}$ & 0.000 & 0.002 & 0.013 & 0.015 \\
\hline$N_{\text {clust }}$ & 31 & 31 & 31 & 31 \\
\hline \multirow[t]{2}{*}{ Some Sex. Violence } & $0.008^{*}$ & $0.010^{*}$ & 0.008 & 0.007 \\
\hline & $(0.004)$ & $(0.005)$ & $(0.006)$ & $(0.006)$ \\
\hline wildboot p-value & {$[0.174]$} & {$[0.202]$} & {$[0.327]$} & {$[0.358]$} \\
\hline \multirow[t]{2}{*}{ Often Sex. Violence } & $0.013^{* *}$ & 0.007 & 0.005 & 0.006 \\
\hline & $(0.006)$ & $(0.005)$ & $(0.006)$ & $(0.006)$ \\
\hline wildboot p-value & {$[0.050]$} & {$[0.214]$} & {$[0.382]$} & {$[0.361]$} \\
\hline Observations & 45185 & 37464 & 37464 & 37464 \\
\hline$R^{2}$ & 0.000 & 0.001 & 0.013 & 0.014 \\
\hline$N_{\text {clust }}$ & 26 & 26 & 26 & 26 \\
\hline Pre-determined Characteristics $X$ & & $\mathrm{Y}$ & $\mathrm{Y}$ & $\mathrm{Y}$ \\
\hline Survey Year FE & & & $\mathrm{Y}$ & $\mathrm{Y}$ \\
\hline Year of Birth FE & & & $\mathrm{Y}$ & $\mathrm{Y}$ \\
\hline Region FE & & & $\mathrm{Y}$ & $\mathrm{Y}$ \\
\hline Country $\times$ Year of Birth FE & & & & $\mathrm{Y}$ \\
\hline
\end{tabular}

Notes: Each cell provides estimates from a separate regression. Regressions in Panel A follow the specification given in equation (2a) and regressions in Panel B follow the specification given in equation $(2 \mathrm{~b})$. These regression specifications are described in sub-section 3.1. Standard errors are clustered at the country level, and ' $N_{\text {clust }}$ ' refers to the number of clusters in each regression; ${ }^{* * *} \mathrm{p}$-value $<1 \%$, $* *$ p-value $<5 \%, *$ p-value $<10 \%$. Wild bootstrap p-values are calculated with 9999 repetitions.

Source: Data from the Demographic and Health Surveys. See Table A1 for the surveys used. 


\section{TABLE 3}

Associations of stillbirth with domestic violence, where violence is experienced by the mother in the last 12 months

\begin{tabular}{|c|c|c|c|c|}
\hline & (I) & (II) & (III) & (IV) \\
\hline Physical Violence & $\begin{array}{c}0.013^{* *} \\
(0.005)\end{array}$ & $\begin{array}{c}0.013^{* * *} \\
(0.003)\end{array}$ & $\begin{array}{l}0.014^{* * *} \\
(0.004)\end{array}$ & $\begin{array}{l}0.014^{* * *} \\
(0.004)\end{array}$ \\
\hline wildboot p-value & {$[0.006]$} & {$[0.004]$} & {$[0.000]$} & {$[0.000]$} \\
\hline Observations & 50214 & 36236 & 36236 & 36236 \\
\hline$R^{2}$ & 0.001 & 0.003 & 0.027 & 0.028 \\
\hline$N_{\text {clust }}$ & 22 & 22 & 22 & 22 \\
\hline Sexual Violence & $\begin{array}{c}0.010^{*} \\
(0.005)\end{array}$ & $\begin{array}{l}0.011^{* *} \\
(0.005)\end{array}$ & $\begin{array}{c}0.014^{* *} \\
(0.005)\end{array}$ & $\begin{array}{c}0.014^{* *} \\
(0.005)\end{array}$ \\
\hline wildboot p-value & {$[0.157]$} & {$[0.094]$} & {$[0.023]$} & {$[0.023]$} \\
\hline Observations & 38279 & 28018 & 28018 & 28018 \\
\hline$R^{2}$ & 0.000 & 0.003 & 0.029 & 0.030 \\
\hline$N_{\text {clust }}$ & 18 & 18 & 18 & 18 \\
\hline Pre-determined Characteristics $X$ & & $\mathrm{Y}$ & $\mathrm{Y}$ & $\mathrm{Y}$ \\
\hline Survey Year FE & & & $\mathrm{Y}$ & $\mathrm{Y}$ \\
\hline Year of Birth FE & & & Y & Y \\
\hline Region FE & & & Y & Y \\
\hline Country $\times$ Year of Birth FE & & & & $\mathrm{Y}$ \\
\hline
\end{tabular}

Notes: Each cell provides estimates from a separate regression. Regressions follow the specification given in equation (3) which is described in sub-section 3.2. Standard errors are clustered at the country level, and ' $N_{\text {clust }}$ ' refers to the number of clusters in each regression; $* * *$ p-value $<1 \%$, ** p-value $<5 \%$, $*$ p-value $<10 \%$. Wild bootstrap p-values are calculated with 9999 repetitions.

Source: Data from the Demographic and Health Surveys. See Table A1 for the surveys used. 
TABLE 4

Selection on unobservables, where violence is ever experienced physical violence by the mother

\begin{tabular}{|c|c|c|c|c|c|}
\hline & $\begin{array}{c}(\mathrm{I}) \\
\text { Restricted } \\
\text { Regression }\end{array}$ & $\begin{array}{l}\text { (II) } \\
\text { Full Controls }\end{array}$ & $\begin{array}{l}\text { (III) } \\
\text { Full Controls } \\
+ \text { Height }\end{array}$ & $\begin{array}{l}\text { (IV) } \\
\text { Full Controls } \\
+ \text { Religion }\end{array}$ & $\begin{array}{l}\quad(\mathrm{V}) \\
\text { Full Controls } \\
+ \text { Height } \\
+ \text { Religion }\end{array}$ \\
\hline \multicolumn{6}{|c|}{ A: Dependent variable $=$ Neonatal Mortality } \\
\hline $\begin{array}{l}\text { Physical Violence } \\
\text { wildboot p-value } \\
\text { Observations } \\
R^{2} \\
\mathrm{AET} \\
\beta_{1}^{*} \\
\delta\end{array}$ & $\begin{array}{r}0.005^{*} \\
(0.003) \\
{[0.070]} \\
1,468,782 \\
0.000\end{array}$ & $\begin{array}{c}0.004^{* * *} \\
(0.001) \\
{[0.000]} \\
1,139,349 \\
0.012 \\
2.661 \\
0.003 \\
4.409\end{array}$ & $\begin{array}{c}0.004^{* * *} \\
(0.001) \\
{[0.000]} \\
935,710 \\
0.013 \\
2.136 \\
0.003 \\
6.708\end{array}$ & $\begin{array}{c}0.005^{* * *} \\
(0.001) \\
{[0.000]} \\
792,286 \\
0.011 \\
33.40 \\
0.004 \\
2.850\end{array}$ & $\begin{array}{c}0.005^{* * *} \\
(0.001) \\
{[0.000]} \\
632,722 \\
0.011 \\
15.21 \\
0.004 \\
3.424\end{array}$ \\
\hline \multicolumn{6}{|c|}{ B: Dependent variable $=$ Infant Mortality } \\
\hline $\begin{array}{l}\text { Physical Violence } \\
\text { wildboot p-value } \\
\text { Observations } \\
R^{2} \\
\mathrm{AET} \\
\beta_{1}^{*} \\
\delta\end{array}$ & $\begin{array}{r}0.010^{* *} \\
(0.005) \\
{[0.068]} \\
1,403,839 \\
0.000\end{array}$ & $\begin{array}{c}0.007^{* * *} \\
(0.001) \\
{[0.000]} \\
1,086,978 \\
0.029 \\
2.448 \\
0.006 \\
4.952\end{array}$ & $\begin{array}{c}0.007^{* * *} \\
(0.001) \\
{[0.000]} \\
893,157 \\
0.030 \\
2.535 \\
0.006 \\
7.900\end{array}$ & $\begin{array}{c}0.008^{* * *} \\
(0.001) \\
{[0.000]} \\
754,245 \\
0.026 \\
7.455 \\
0.006 \\
3.039\end{array}$ & $\begin{array}{c}0.009^{* * *} \\
(0.001) \\
{[0.000]} \\
602,983 \\
0.027 \\
8.293 \\
0.007 \\
4.431\end{array}$ \\
\hline \multicolumn{6}{|c|}{ C: Dependent variable $=$ Under-5 Mortality } \\
\hline $\begin{array}{l}\text { Physical Violence } \\
\text { wildboot p-value } \\
\text { Observations } \\
R^{2} \\
\mathrm{AET} \\
\beta_{1}^{*} \\
\delta\end{array}$ & $\begin{array}{r}0.013^{*} \\
(0.007) \\
{[0.152]} \\
1,118,738 \\
0.000 \\
0\end{array}$ & $\begin{array}{c}0.010^{* * *} \\
(0.002) \\
{[0.000]} \\
857,086 \\
0.054 \\
3.215 \\
0.008 \\
5.161\end{array}$ & $\begin{array}{c}0.010^{* * *} \\
(0.002) \\
{[0.000]} \\
704,360 \\
0.055 \\
3.056 \\
0.009 \\
8.063\end{array}$ & $\begin{array}{c}0.013^{* * *} \\
(0.001) \\
{[0.000]} \\
588,640 \\
0.050 \\
20.33 \\
0.010 \\
3.750\end{array}$ & $\begin{array}{c}0.012^{* * *} \\
(0.001) \\
{[0.001]} \\
472,030 \\
0.051 \\
14.49 \\
0.011 \\
6.348\end{array}$ \\
\hline $\begin{array}{l}\text { Fixed Effects } \\
\text { Pre-determined Characteristics } X \\
\text { Height } \\
\text { Religion }\end{array}$ & & $\begin{array}{l}\mathrm{Y} \\
\mathrm{Y}\end{array}$ & $\begin{array}{l}\mathrm{Y} \\
\mathrm{Y} \\
\mathrm{Y}\end{array}$ & $\begin{array}{l}\mathrm{Y} \\
\mathrm{Y} \\
\mathrm{Y}\end{array}$ & $\begin{array}{l}\mathrm{Y} \\
\mathrm{Y} \\
\mathrm{Y} \\
\mathrm{Y}\end{array}$ \\
\hline
\end{tabular}

Notes: Each cell provides estimates from a separate regression. Regressions follow the specification given in equation (1) which is described in sub-section 3.1, with additional controls as specified in the Table. 'Fixed Effects' refers to Survey Year Fixed Effects, Year of Birth Fixed Effects, Country $\times$ Year of Birth Fixed Effects and Region Fixed Effects. Standard errors are clustered at the country level; *** p-value $<1 \%$, ** p-value $<5 \%,{ }^{*}$ p-value $<10 \%$. The wild bootstrap p-values shown are calculated with 9999 repetitions. 'AET' indicates the Altonji, Taber Elder ratio. $\beta_{1}^{*}$ is our estimated lower bound effect, under the assumption of equal selection on observables and unobservables. $\delta$ is our estimate of the selection ratio parameter; this specifies the ratio of selection on unobservables to observables that would be needed to explain away our estimated effect.

Source: Data from the Demographic and Health Surveys. See Table A1 for the surveys used. 
TABLE 5

Selection on unobservables, where violence is ever experienced sexual violence by the mother



Notes: Each cell provides estimates from a separate regression. Regressions follow the specification given in equation (1) which is described in sub-section 3.1, with additional controls as specified in the Table. 'Fixed Effects' refers to Survey Year Fixed Effects, Year of Birth Fixed Effects, Country $\times$ Year of Birth Fixed Effects and Region Fixed Effects. Standard errors are clustered at the country level; *** p-value $<1 \%$, ** p-value $<5 \%, *$ p-value $<10 \%$. The wild bootstrap p-values shown are calculated with 9999 repetitions. 'AET' indicates the Altonji, Taber Elder ratio. $\beta_{1}^{*}$ is our estimated lower bound effect, under the assumption of equal selection on observables and unobservables. $\delta$ is our estimate of the selection ratio parameter; this specifies the ratio of selection on unobservables to observables that would be needed to explain away our estimated effect.

Source: Data from the Demographic and Health Surveys. See Table A1 for the surveys used. 


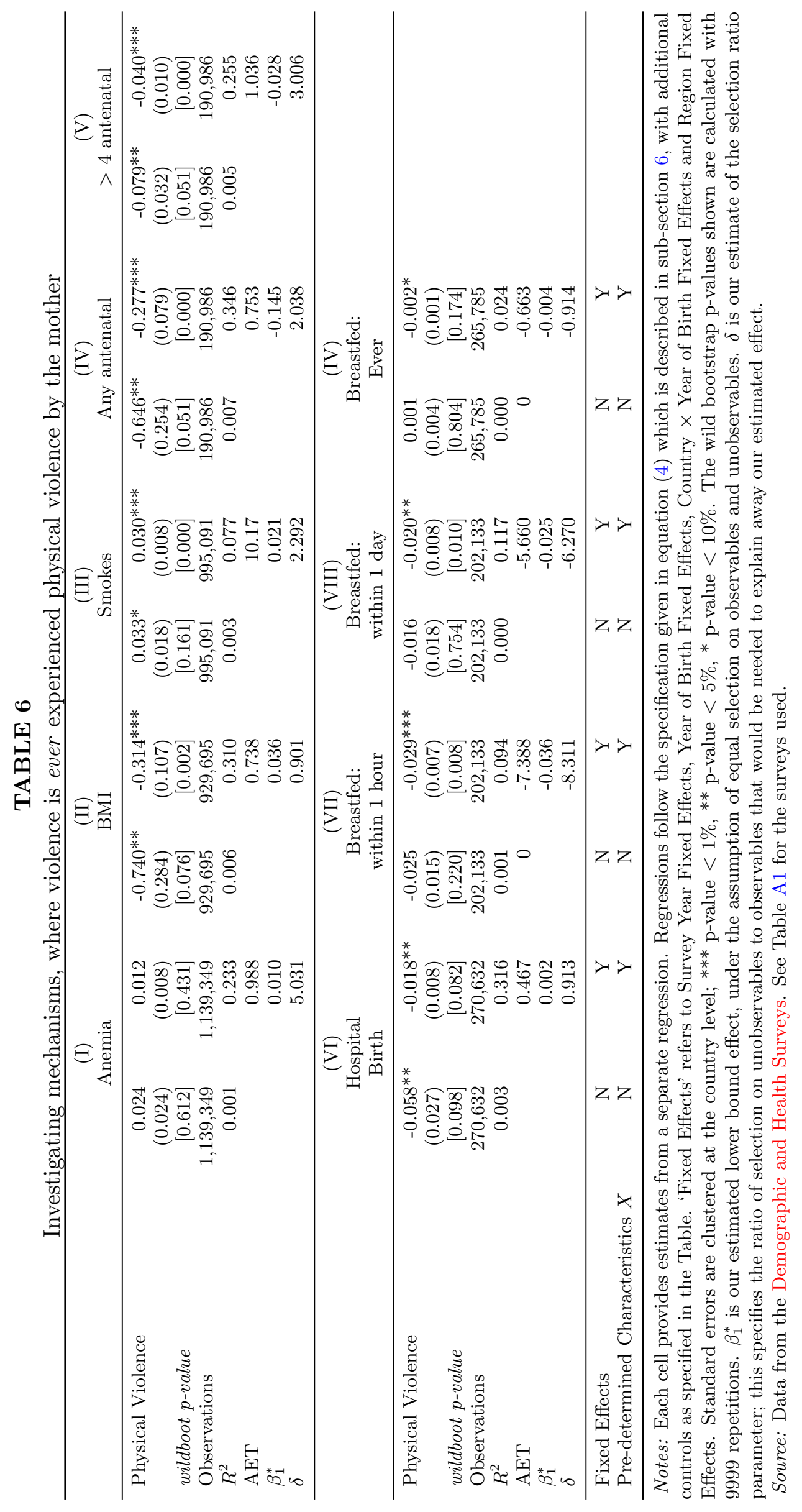




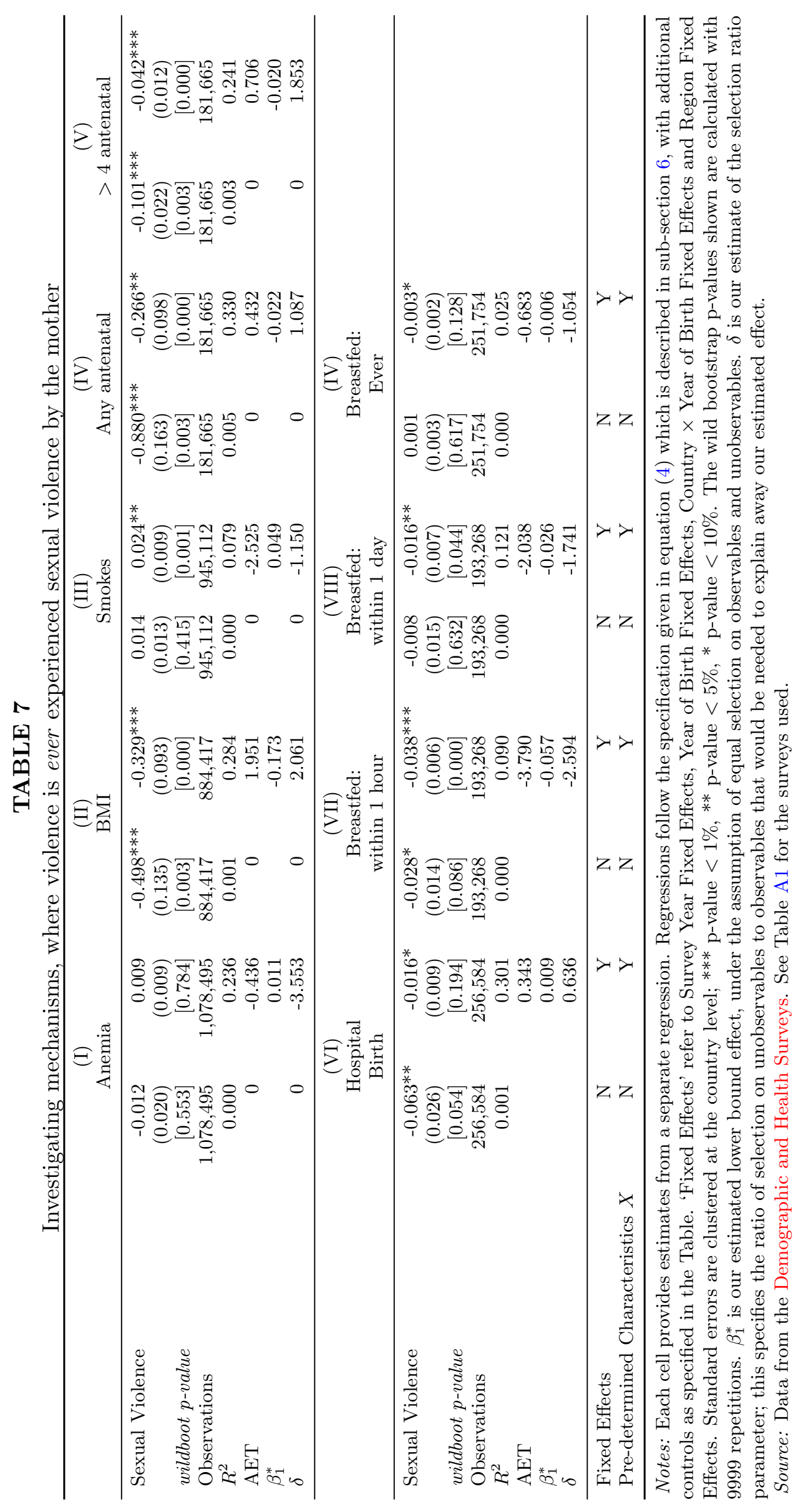




\section{Supplementary material}

\section{Appendix A: Additional data descriptives}

\section{Domestic violence}

Figure A2 shows variation in reported physical and sexual violence across surveys used in the estimation sample. There is variation in these measures both across countries and within a particular country at different points in time. In general the rates of domestic violence ever experienced are highest in Asian countries (such as Bangladesh) and in African countries. In the 2007 Democratic Republic of Congo survey the rate of ever experienced physical violence is $53.20 \%$. Rates of sexual violence are also highest in African countries, particularly the Democratic Republic of Congo and Uganda. For all other countries rates of sexual violence are close to or less than $20 \%$.

As expected, rates of physical and sexual violence in the last twelve months are lower than rates of violence ever experienced (Figure A3). The overall patterns in violence experienced in the last twelve months are similar to violence ever experienced across countries and over time.

\section{Child mortality}

We observe across country and time variation in mortality suffered by children in our estimation sample (Figure A4). These mortality rates are higher in African countries such as Mali as well as Asian countries such as Bangladesh and Pakistan. Neonatal mortality reaches a high of 5.98\%, infant mortality reaches a high of $13.83 \%$ and under-5 mortality reaches a high of $24.58 \%$. 


\section{Figure A1}

Map of countries included in estimation sample

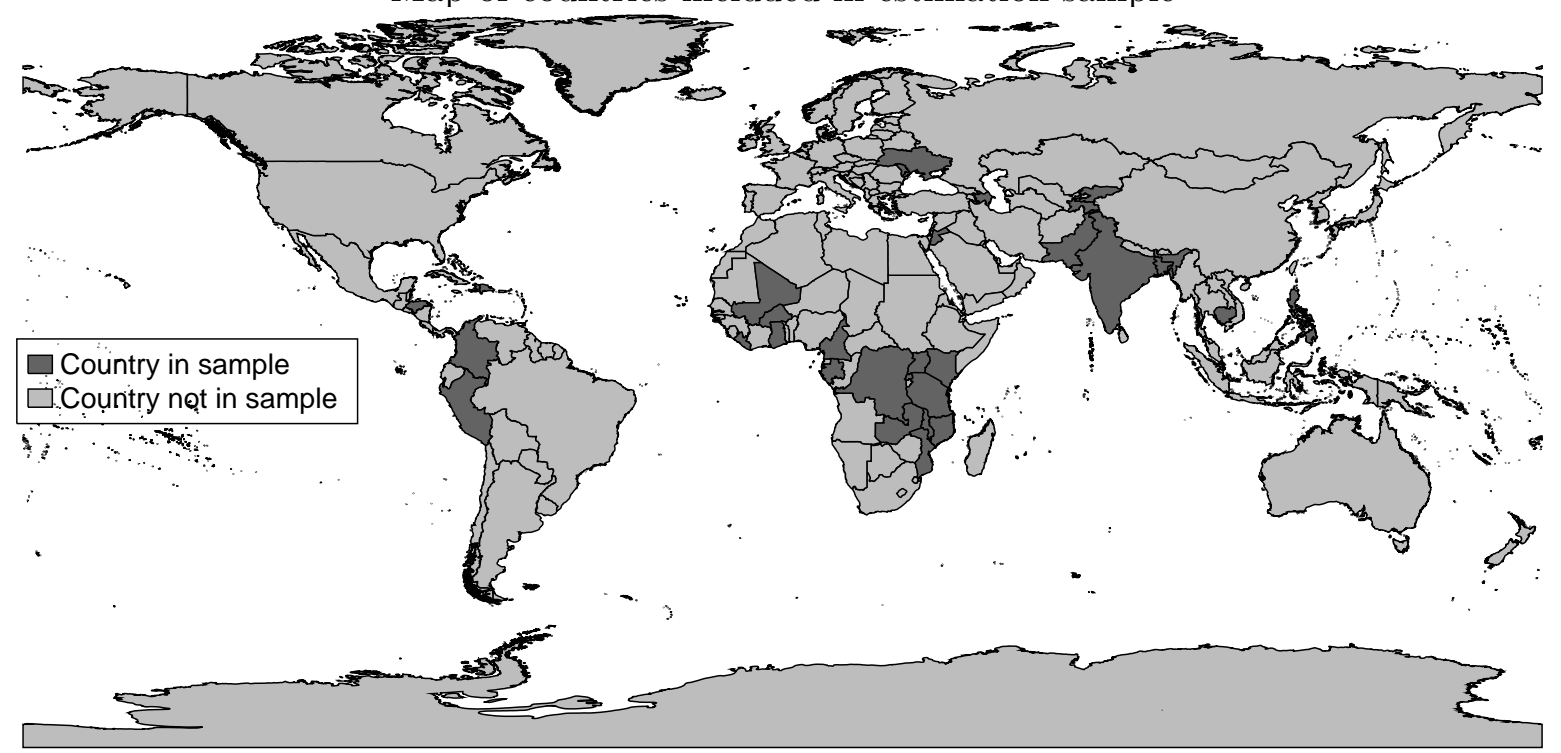

Source: Data from the Demographic and Health Surveys. 


\section{Figure A2}

Domestic violence measures by DHS survey

(a) Spouse physical violence ever experienced

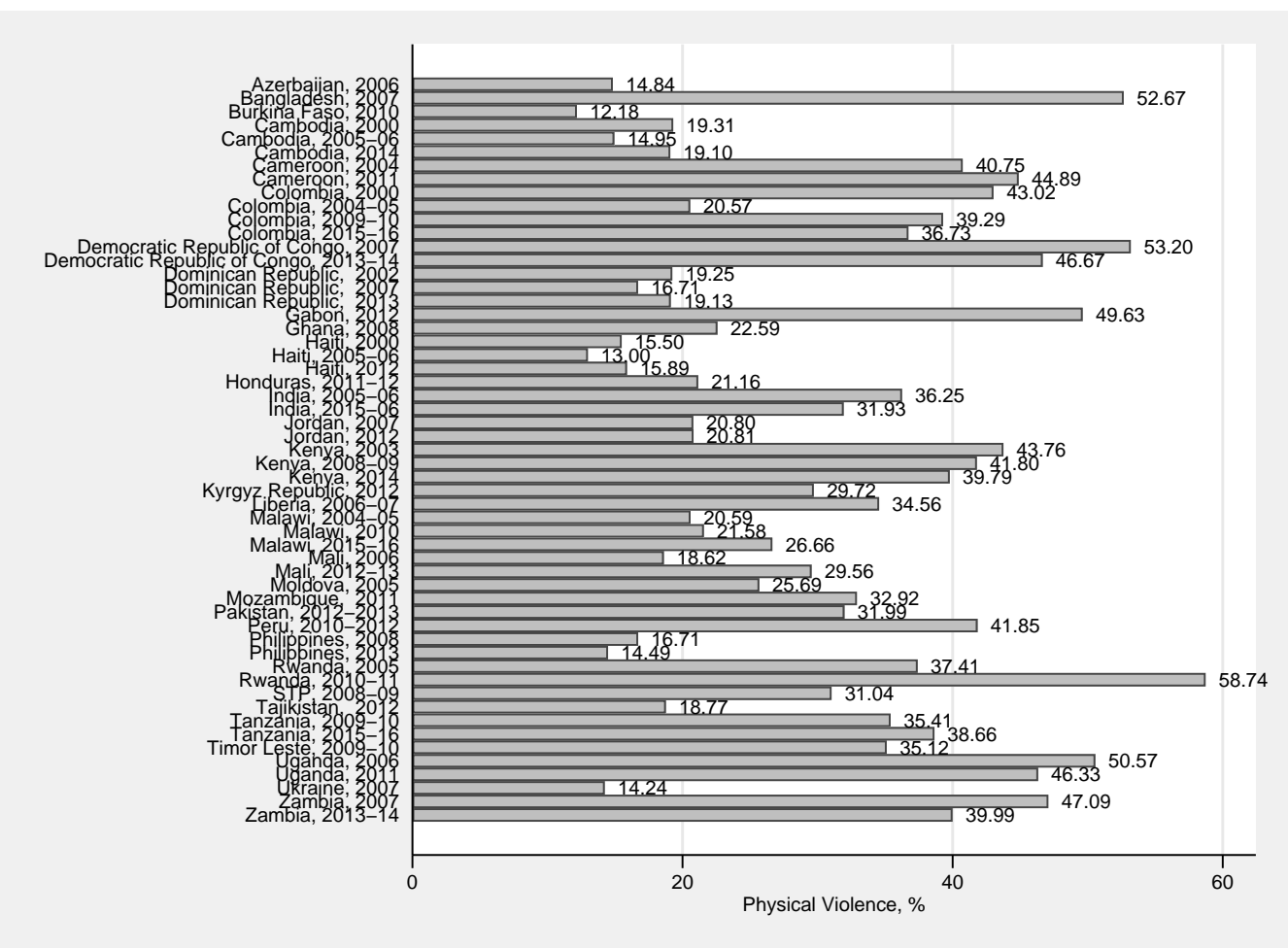

(b) Spouse sexual violence ever experienced



Source: Data from the Demographic and Health Surveys. Estimation sample is that from baseline regressions investigating violence ever experienced with a full set of controls (Equation 1). 


\section{Figure A3}

Domestic violence measures by DHS survey

(a) Spouse physical violence in last 12 months

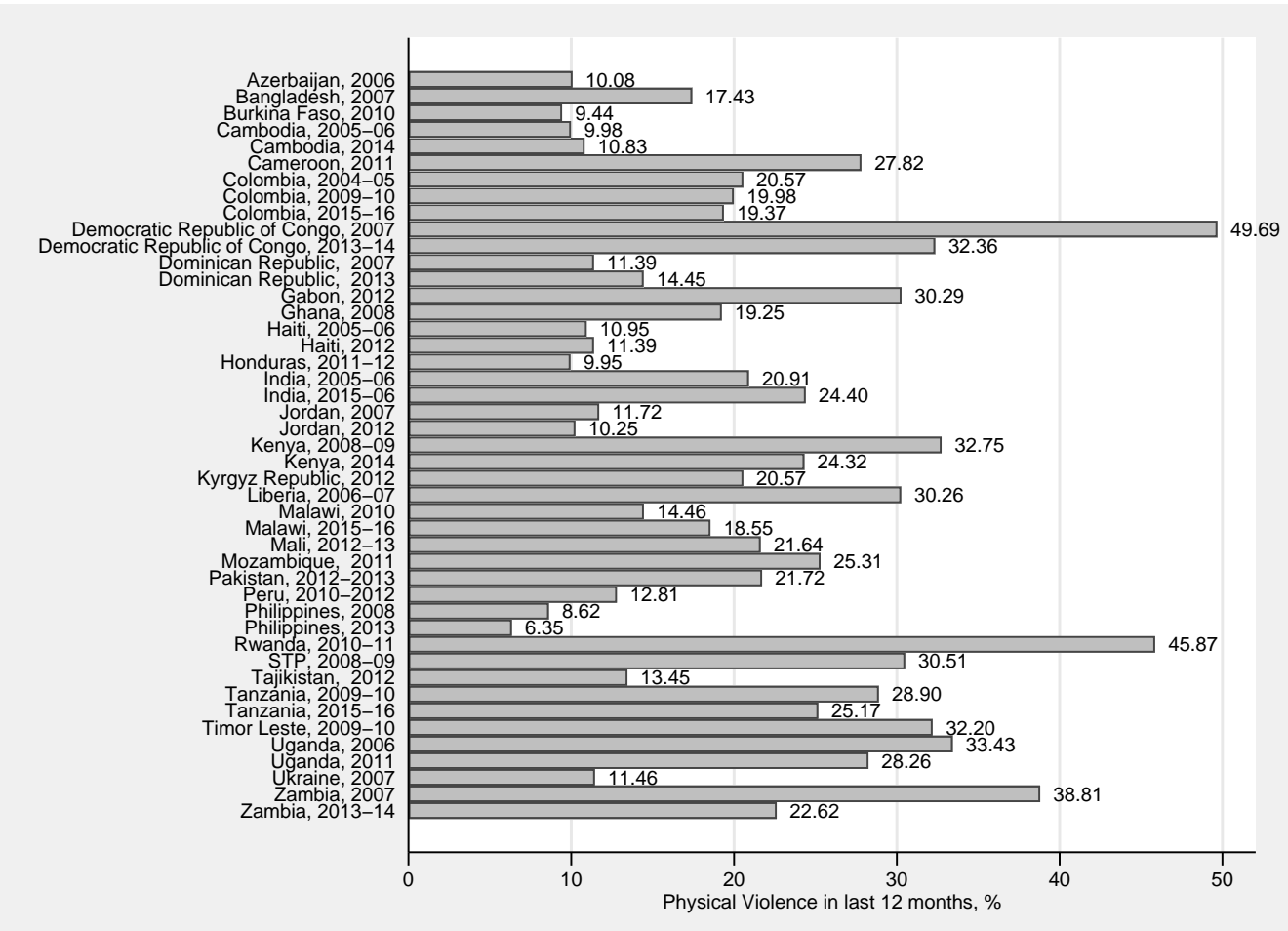

(b) Spouse sexual violence in last 12 months

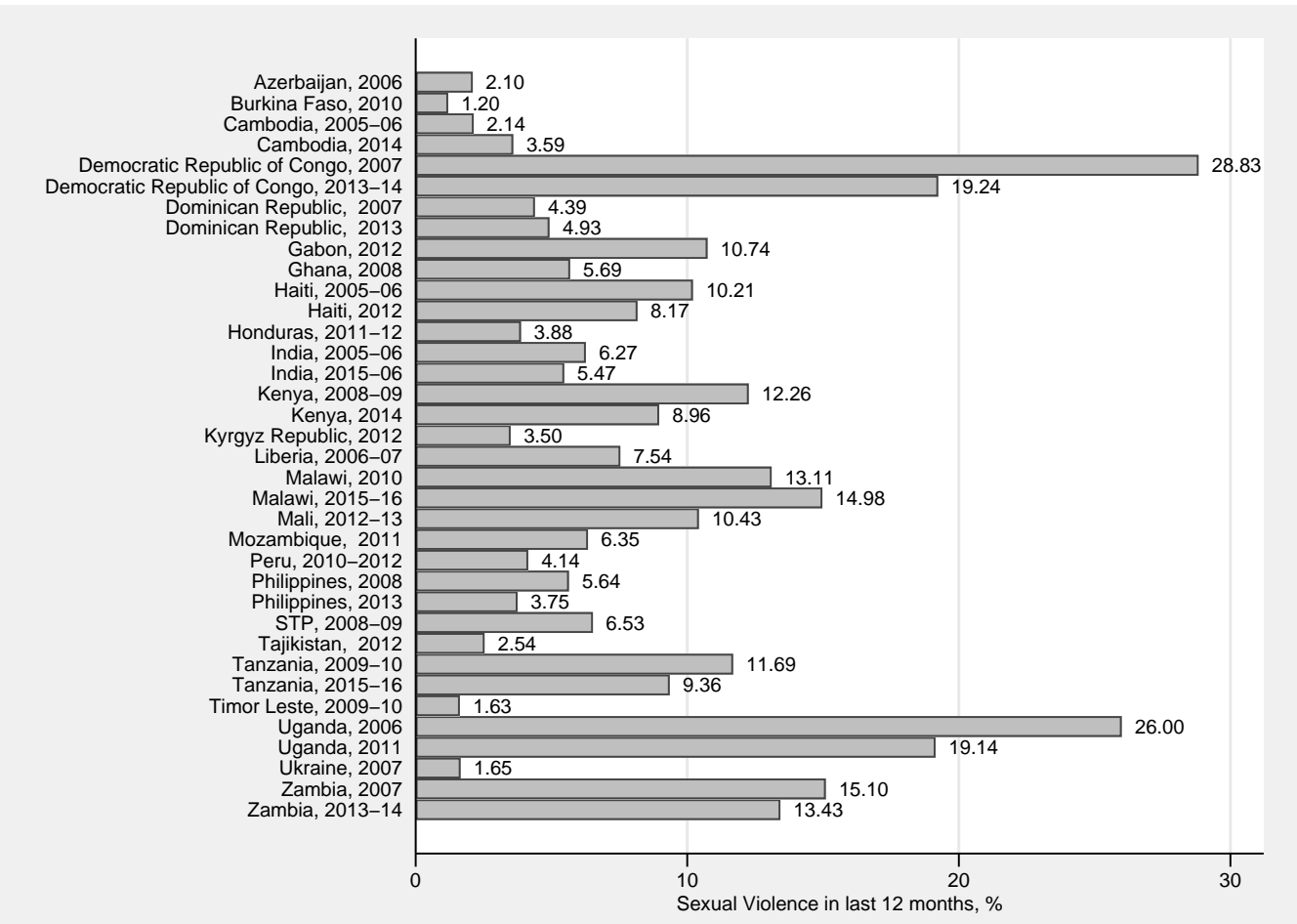

Source: Data from the Demographic and Health Surveys. Estimation sample is that from baseline regressions investigating violence experienced in the last 12 months with a full set of controls (Equation 2a). 


\section{Figure A4}

Child mortality by DHS survey

(a) Neonatal Mortality

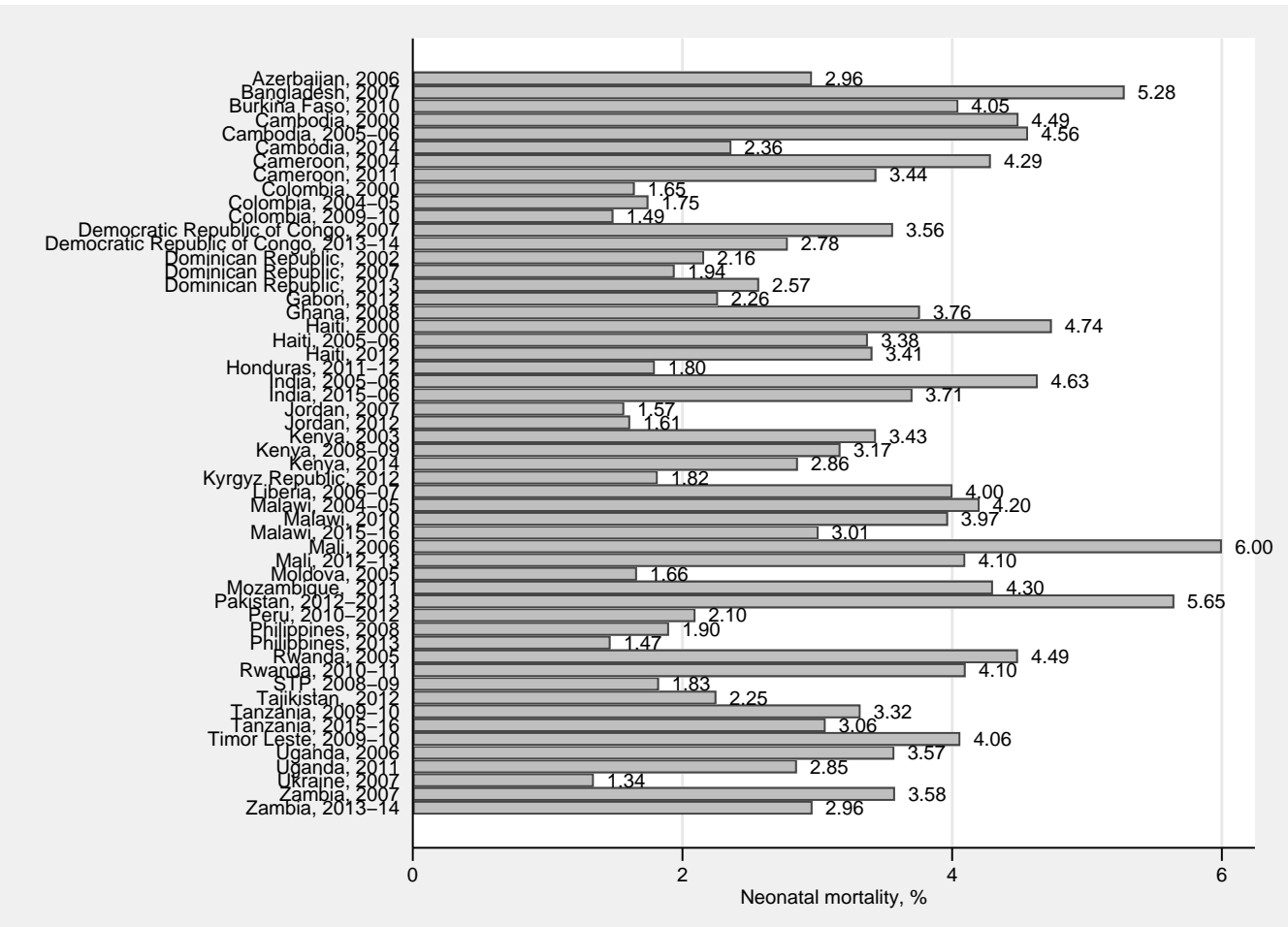

(b) Infant Mortality

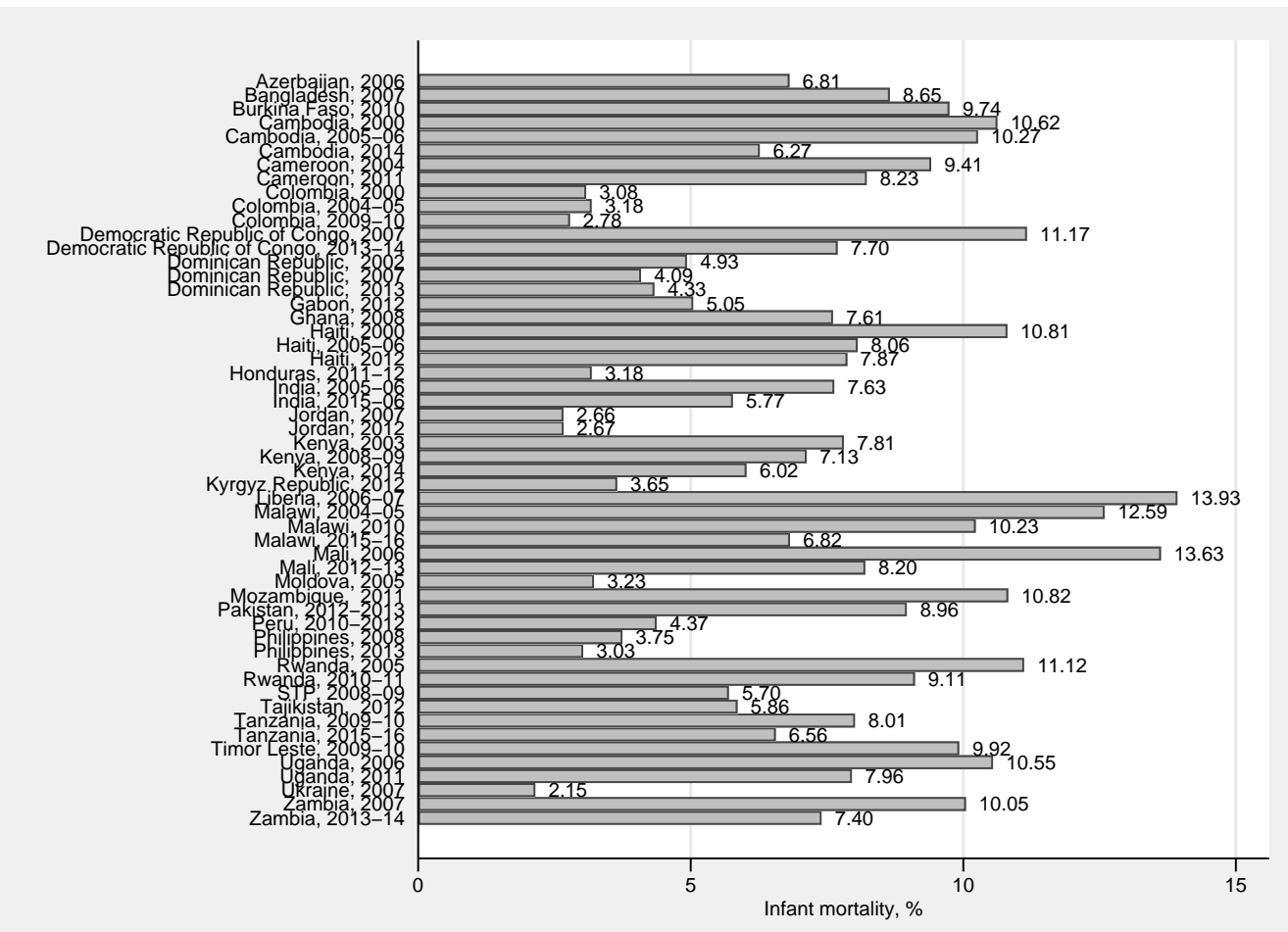

Source: Data from the Demographic and Health Surveys. Estimation sample is that from baseline regressions investigating physical violence ever experienced with a full set of controls (Equation 1). 


\section{Figure A4}

Child mortality by DHS survey

(c) Under-5 Mortality

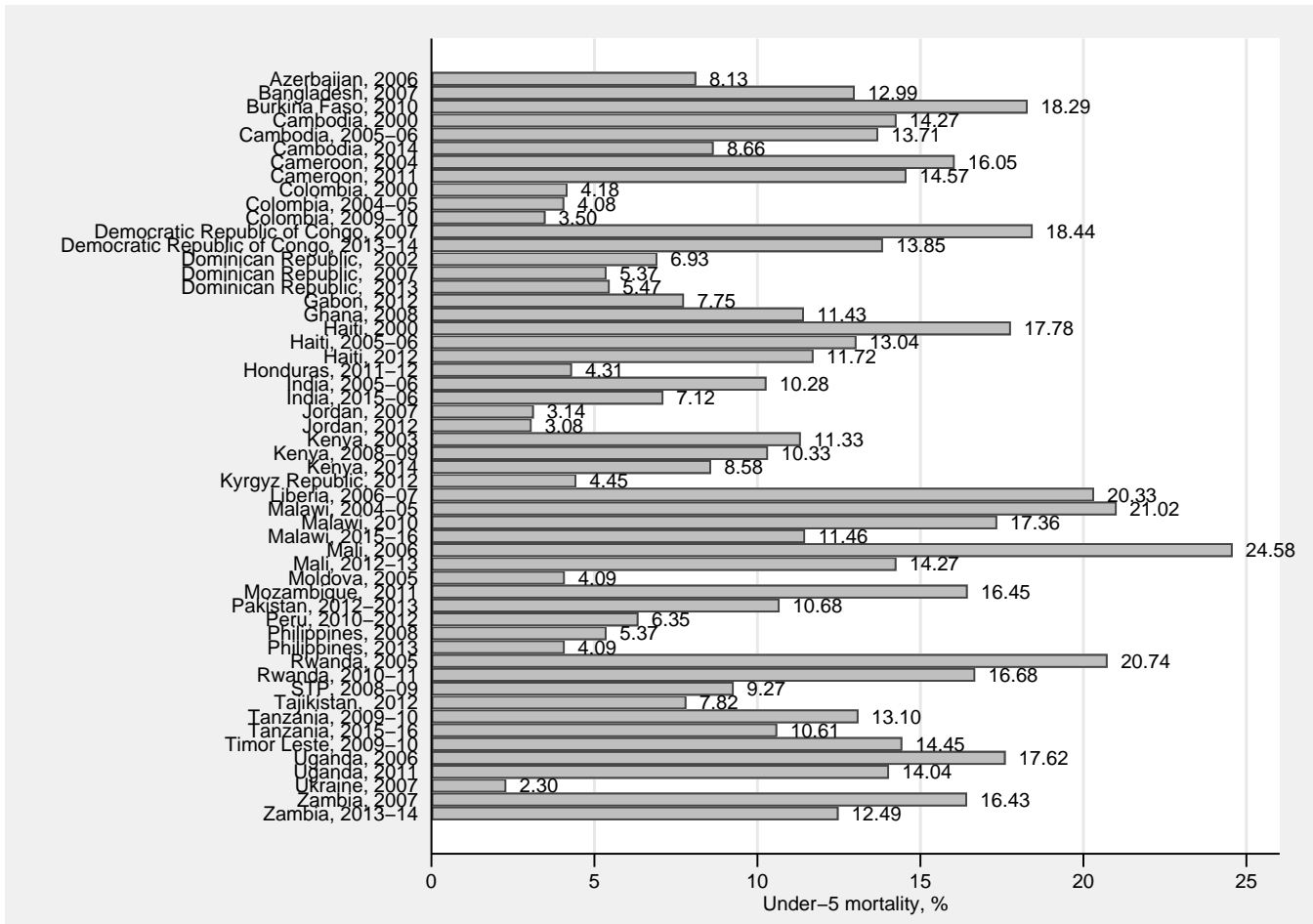

Source: Data from the Demographic and Health Surveys. Estimation sample is that from baseline regressions investigating physical violence experienced in the last 12 months with a full set of controls (Equation 2a). 


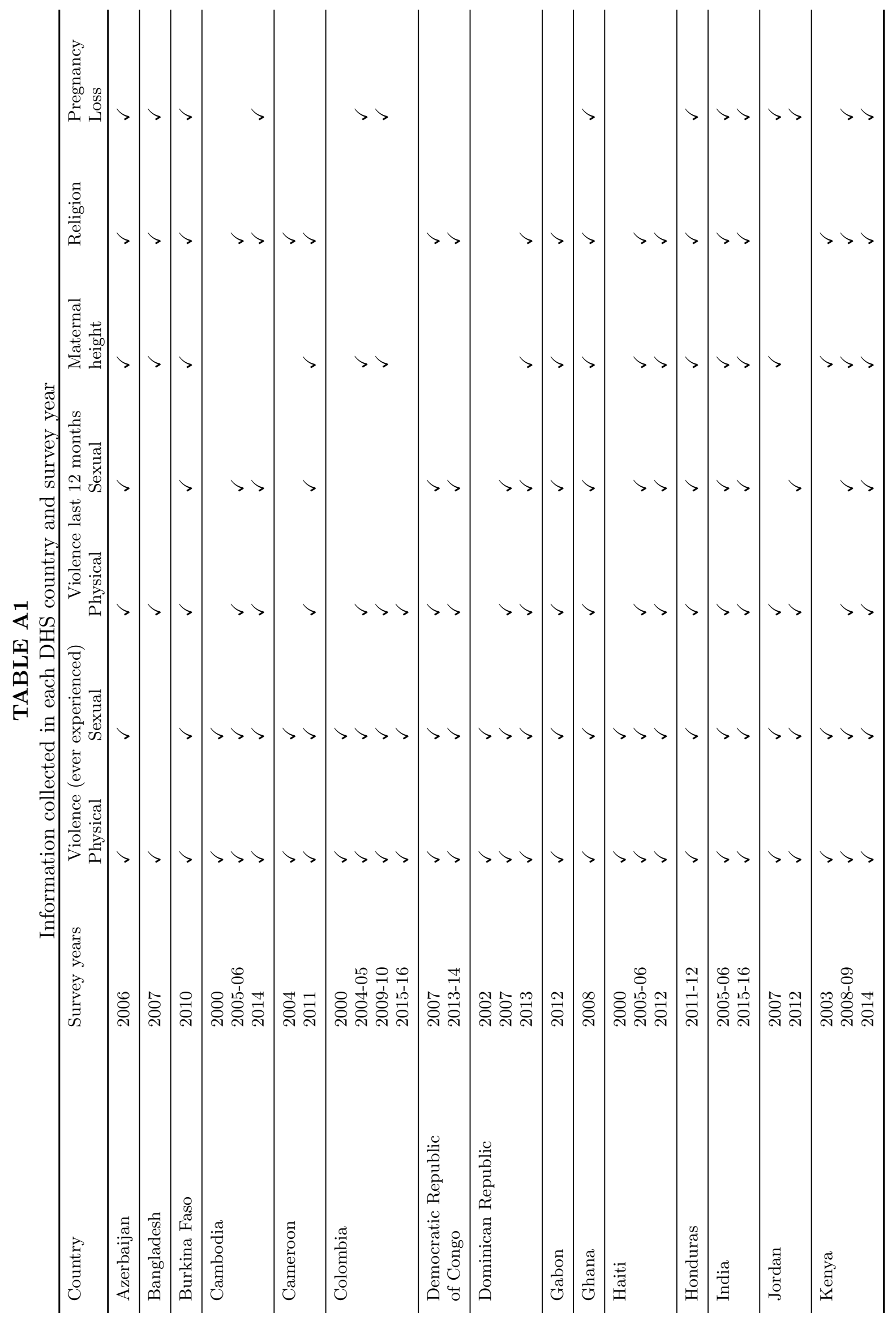




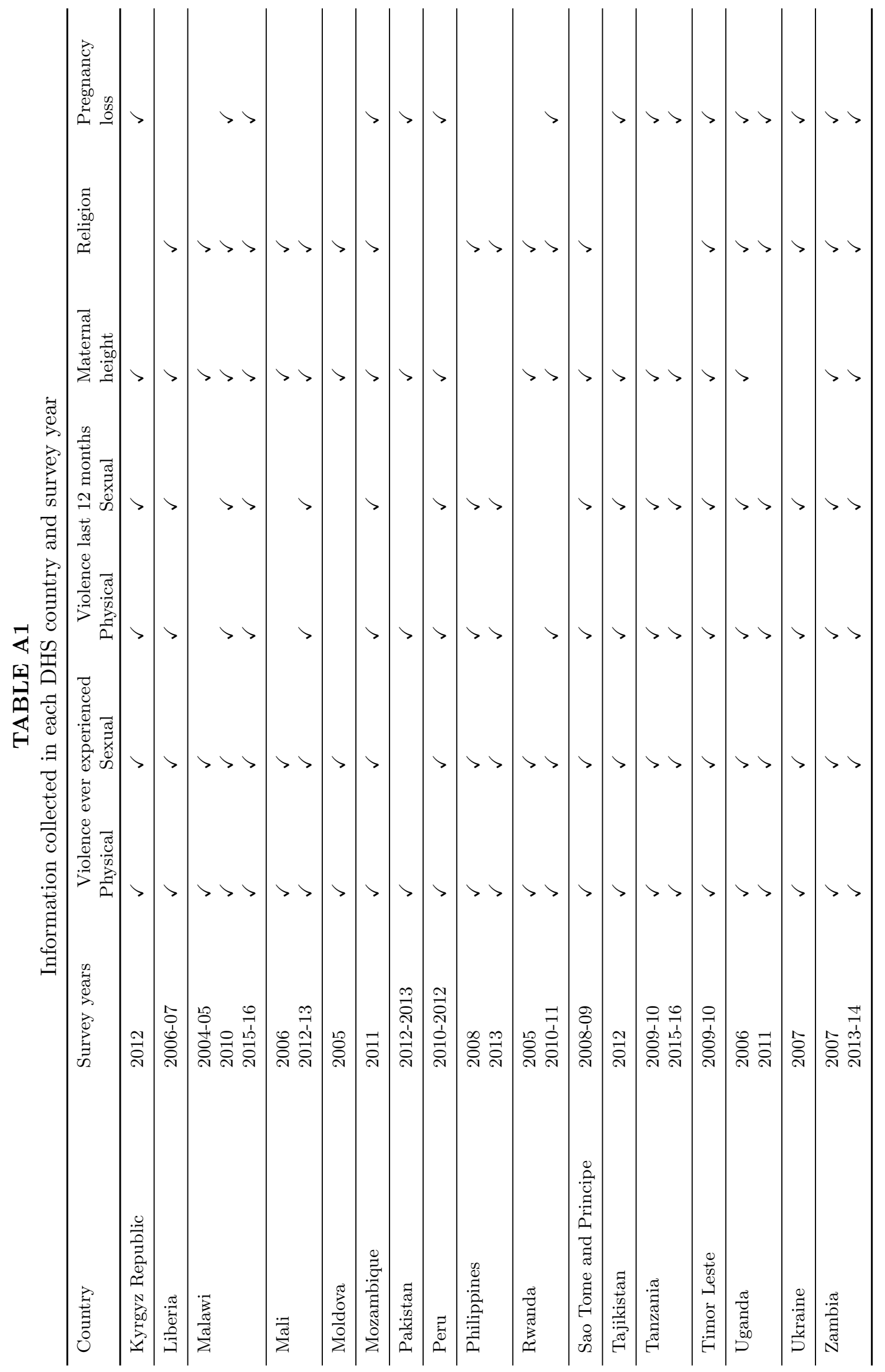




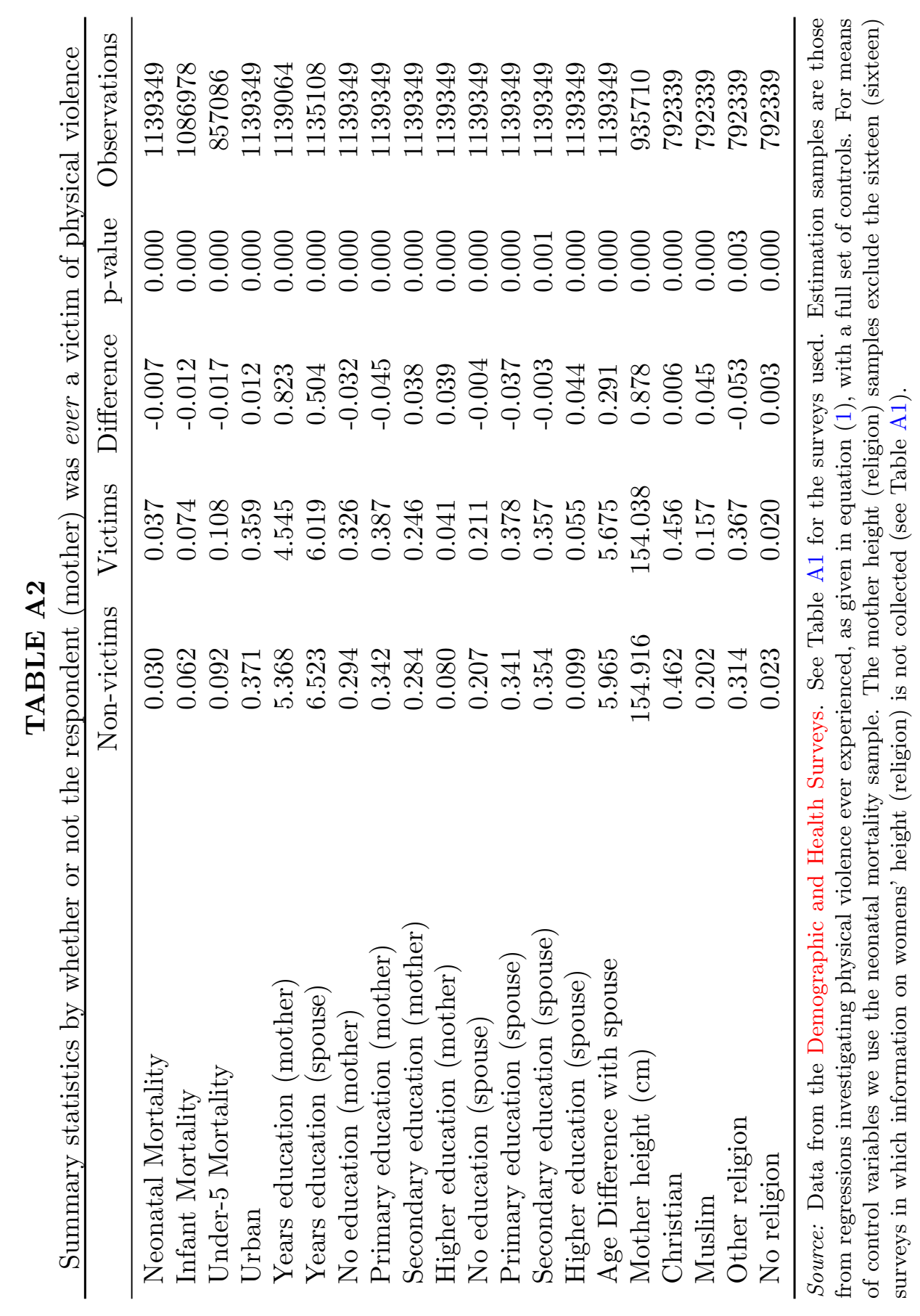




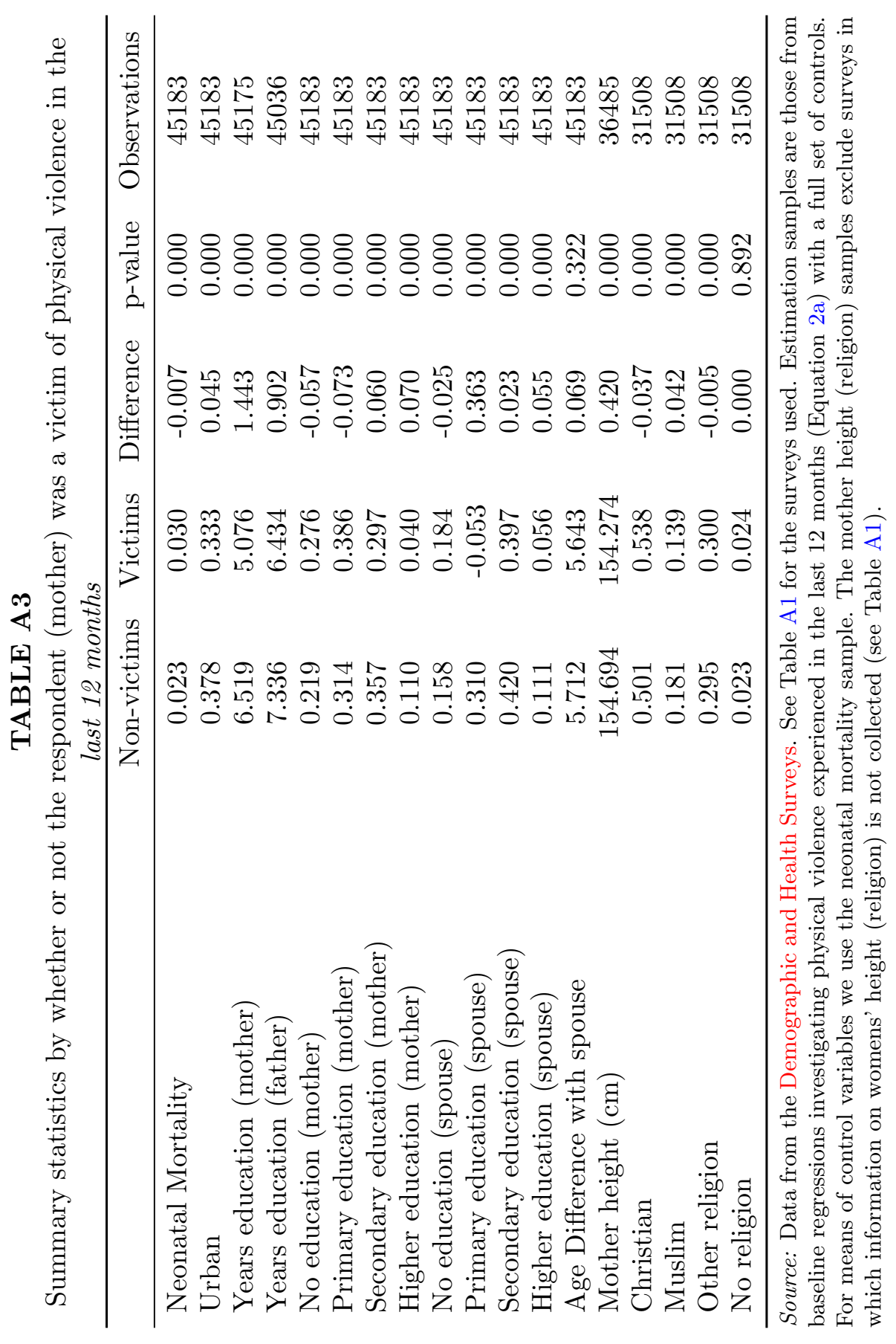




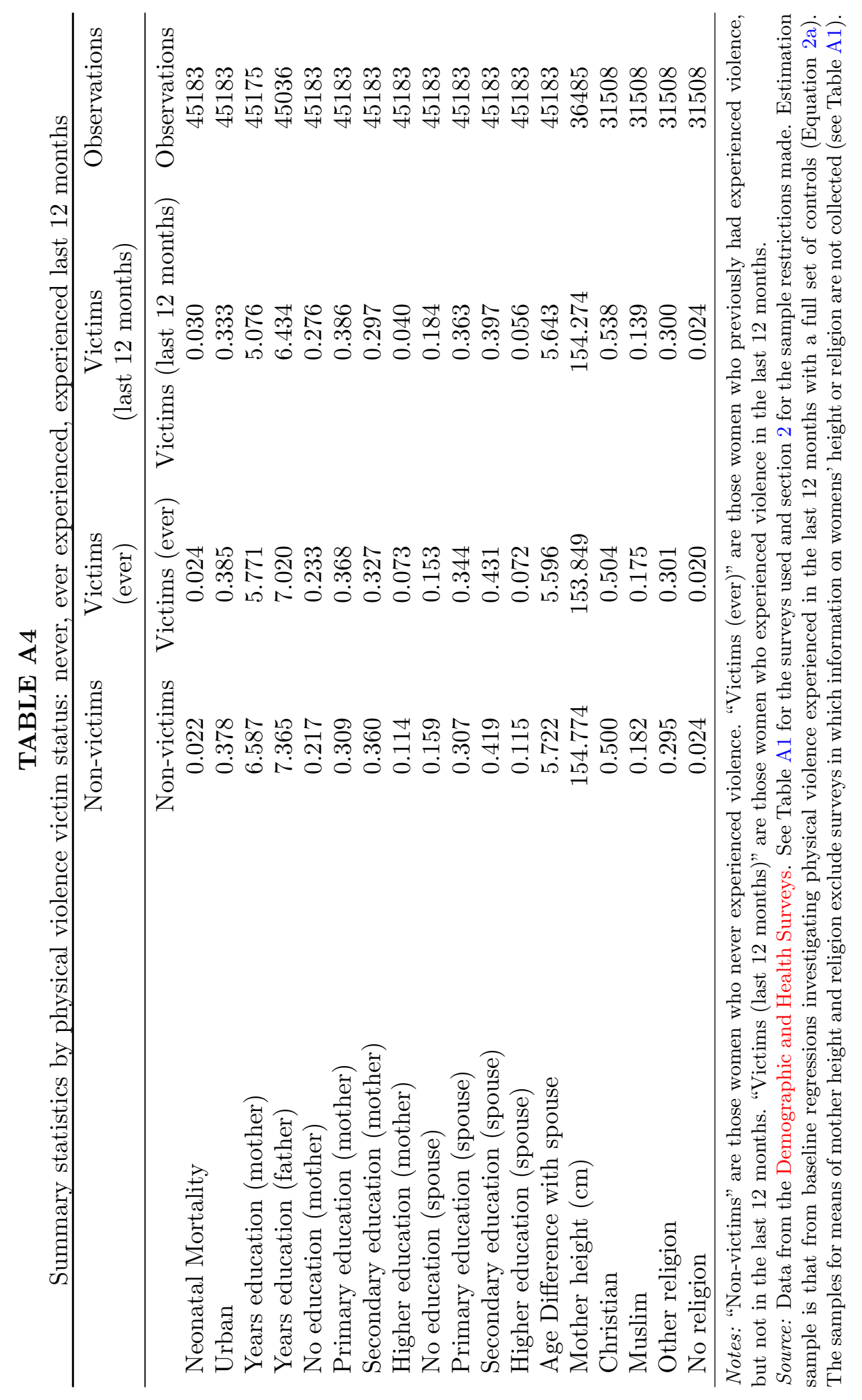


TABLE A5

Robustness check: Placebo regressions

\begin{tabular}{lrrrr}
\hline & $(\mathrm{I})$ & \multicolumn{1}{c}{$(\mathrm{II})$} & \multicolumn{1}{c}{$(\mathrm{III})$} & \multicolumn{1}{c}{$(\mathrm{IV})$} \\
\hline Physical Violence & 0.001 & 0.001 & 0.001 & 0.001 \\
& $(0.004)$ & $(0.004)$ & $(0.003)$ & $(0.003)$ \\
wildboot p-value & {$[0.746]$} & {$[0.805]$} & {$[0.856]$} & {$[0.768]$} \\
Observations & 44594 & 35996 & 35996 & 35996 \\
$R^{2}$ & 0.000 & 0.001 & 0.016 & 0.019 \\
$N_{\text {clust }}$ & 31.000 & 31.000 & 31.000 & 31.000 \\
Sexual Violence & & & & \\
& 0.004 & 0.004 & 0.007 & 0.007 \\
wildboot p-value & $(0.004)$ & $(0.005)$ & $(0.005)$ & $(0.005)$ \\
Observations & {$[0.444]$} & {$[0.419]$} & {$[0.205]$} & {$[0.217]$} \\
$R^{2}$ & 50781 & 40560 & 40560 & 40560 \\
$N_{\text {clust }}$ & 0.000 & 0.001 & 0.013 & 0.015 \\
\hline Pre-determined Characteristics $X$ & 29.000 & 29.000 & 29.000 & 29.000 \\
Country FE & & $\mathrm{Y}$ & $\mathrm{Y}$ & $\mathrm{Y}$ \\
Year FE & & & $\mathrm{Y}$ & $\mathrm{Y}$ \\
Region FE & & & $\mathrm{Y}$ & $\mathrm{Y}$ \\
Country $\times$ Year FE & & & & $\mathrm{Y}$ \\
\hline
\end{tabular}

Notes: Each cell provides estimates from a separate placebo regression, in which we (incorrectly) treat women who ever experienced violence (historically) but not in the last 12 months, as having experienced violence in the last 12 month (recent violence). Regressions follow the specification given in equation (2a) with the placebo regressions described in sub-section 4.1.2. Standard errors are clustered at the country level, and ' $N_{\text {clust }}$ ' refers to the number of clusters in each regression; $* * *$ p-value $<1 \%$, ** p-value $<5 \%$, * p-value $<10 \%$. The wild bootstrap p-values shown are calculated with 9999 repetitions.

Source: Data from the Demographic and Health Surveys. See Table A1 for the surveys used. 
TABLE A6

Associations of pregnancy loss/termination with domestic violence, where violence is experienced by the mother in the last 12 months

\begin{tabular}{lcccc}
\hline & $(\mathrm{I})$ & $(\mathrm{II})$ & $(\mathrm{III})$ & $(\mathrm{IV})$ \\
\hline Physical Violence & $0.038^{* * *}$ & $0.044^{* * *}$ & $0.045^{* * *}$ & $0.046^{* * *}$ \\
& $(0.011)$ & $(0.007)$ & $(0.009)$ & $(0.009)$ \\
wildboot p-value & {$[0.006]$} & {$[0.001]$} & {$[0.000]$} & {$[0.000]$} \\
Observations & 57424 & 41786 & 41786 & 41786 \\
$R^{2}$ & 0.002 & 0.020 & 0.070 & 0.071 \\
$N_{\text {clust }}$ & 22 & 22 & 22 & 22 \\
Sexual Violence & & & & \\
& $0.044^{* *}$ & $0.066^{* * *}$ & $0.067^{* * *}$ & $0.067^{* * *}$ \\
wildboot p-value & $(0.016)$ & $(0.015)$ & $(0.010)$ & $(0.010)$ \\
Observations & {$[0.041]$} & {$[0.005]$} & {$[0.000]$} & {$[0.000]$} \\
$R^{2}$ & 43500 & 32178 & 32178 & 32178 \\
$N_{\text {clust }}$ & 0.001 & 0.026 & 0.087 & 0.088 \\
\hline Pre-determined Characteristics $X$ & 18 & 18 & 18 & 18 \\
Survey Year FE & & $\mathrm{Y}$ & $\mathrm{Y}$ & $\mathrm{Y}$ \\
Year of Birth FE & & & $\mathrm{Y}$ & $\mathrm{Y}$ \\
Region FE & & & $\mathrm{Y}$ & $\mathrm{Y}$ \\
Country $\times$ Year of Birth FE & & & $\mathrm{Y}$ & $\mathrm{Y}$ \\
\hline
\end{tabular}

Notes: Each cell provides estimates from a separate regression. Regressions follow the specification given in equation (3) which is described in sub-section 3.2. Standard errors are clustered at the country level, and ' $N_{\text {clust }}$ ' refers to the number of clusters in each regression; *** p-value $<1 \%$, ** p-value $<5 \%$, * p-value $<10 \%$. The wild bootstrap p-values shown are calculated with 9999 repetitions.

Source: Data from the Demographic and Health Surveys. See Table A1 for the surveys used. 
TABLE A7

Selection on unobservables, where violence is experienced by the mother in the last 12 months

\begin{tabular}{|c|c|c|c|c|c|}
\hline & $\begin{array}{c}(\mathrm{I}) \\
\text { Restricted } \\
\text { Regression }\end{array}$ & $\begin{array}{l}(\mathrm{II}) \\
\text { Full Controls }\end{array}$ & $\begin{array}{c}\quad(\mathrm{III}) \\
\text { Full Controls } \\
+ \text { Height }\end{array}$ & $\begin{array}{c}\text { (IV) } \\
\text { Full Controls } \\
+ \text { Religion }\end{array}$ & $\begin{array}{c}(\mathrm{V}) \\
\text { Full Controls } \\
+ \text { Height } \\
+ \text { Religion }\end{array}$ \\
\hline Physical Violence & $\begin{array}{l}0.007^{* * *} \\
(0.002)\end{array}$ & $\begin{array}{c}0.004^{*} \\
(0.002)\end{array}$ & $\begin{array}{c}0.004^{* *} \\
(0.002)\end{array}$ & $\begin{array}{l}0.006^{* * *} \\
(0.002)\end{array}$ & $\begin{array}{c}0.007^{* *} \\
(0.003)\end{array}$ \\
\hline wildboot p-value & {$[0.006]$} & {$[0.149]$} & {$[0.115]$} & {$[0.041]$} & {$[0.047]$} \\
\hline Observations & 56,235 & 45,183 & 36,485 & 31,505 & 24,310 \\
\hline$R^{2}$ & 0.000 & 0.015 & 0.015 & 0.014 & 0.014 \\
\hline AET & 0 & 1.292 & 1.747 & 6.840 & 25.71 \\
\hline$\beta_{1}^{*}$ & & 0.003 & 0.004 & 0.005 & 0.006 \\
\hline$\delta$ & 0 & 4.974 & 7.826 & 5.191 & 8.273 \\
\hline Sexual Violence & $0.009 * *$ & 0.007 & $0.012^{*}$ & $0.008 * *$ & $0.014^{* * *}$ \\
\hline & $(0.004)$ & $(0.006)$ & $(0.006)$ & $(0.004)$ & $(0.004)$ \\
\hline wildboot p-value & {$[0.097]$} & [0.339] & {$[0.256]$} & {$[0.275]$} & [0.198] \\
\hline Observations & 45,185 & 37,464 & 29,629 & 30,006 & 22,799 \\
\hline$R^{2}$ & 0.000 & 0.014 & 0.014 & 0.014 & 0.014 \\
\hline $\mathrm{AET}$ & 0 & 2.843 & -5.058 & 9.875 & -2.849 \\
\hline$\beta_{1}^{*}$ & & 0.006 & 0.011 & 0.008 & 0.014 \\
\hline$\delta$ & 0 & 6.054 & 13.02 & 7.339 & 16.740 \\
\hline Fixed Effects & & $\mathrm{Y}$ & $\mathrm{Y}$ & $\mathrm{Y}$ & $\mathrm{Y}$ \\
\hline Pre-determined Characteristics $X$ & & Y & $\mathrm{Y}$ & $\mathrm{Y}$ & Y \\
\hline Height & & & $\mathrm{Y}$ & & $\mathrm{Y}$ \\
\hline Religion & & & & $\mathrm{Y}$ & Y \\
\hline
\end{tabular}

Notes: The dependent variable in all regressions is neonatal mortality. Each cell provides estimates from a separate regression. Regressions use the specification given in equation (2a) which is described in sub-section 3.1, with additional controls as specified in the Table. 'Fixed Effects' refer to Survey Year Fixed Effects, Year of Birth Fixed Effects, Country $\times$ Year of Birth Fixed Effects and Region Fixed Effects. Standard errors are clustered at the country level; ${ }^{* * *}$ p-value $<1 \%,{ }^{* *}$ p-value $<5 \%,{ }^{*}$ p-value $<10 \%$. The wild bootstrap p-values shown are calculated with 9999 repetitions. $\beta_{1}^{*}$ is our estimated lower bound effect, under the assumption of equal selection on observables and unobservables. $\delta$ is our estimate of the selection ratio parameter; this specifies the ratio of selection on unobservables to observables that would be needed to explain away our estimated effect.

Source: Data from the Demographic and Health Surveys. See Table A1 for the surveys used. 